\title{
OPEN Effect of hypoxia factors gene silencing on ROS production and metabolic status of A375 malignant melanoma cells
}

\author{
Ivana Špakovái ${ }^{\text {, Miroslava Rabajdová1 }}{ }^{\text {, Helena Mičková2 }}{ }^{\text {, Wolfgang F. Graier }}{ }^{3,4}$ \& \\ Mária Mareková ${ }^{1}$
}

The innate response of melanocytes to exogenous or endogenous stress stimuli like extreme pH and temperature, metabolite and oxygen deficiency or a high UV dose initiates a cellular stress response. This process activates adaptive processes to minimize the negative impact of the stressor on the pigment cell. Under physiological conditions, a non-cancer cell is directed to apoptosis if the stressor persists. However, malignant melanoma cells will survive persistent stress thanks to distinct "cancerous" signaling pathways (e.g. MEK) and transcription factors that regulate the expression of so-called "survival genes" (e.g. HIF, MITF). In this survival response of cancer cells, MEK pathway directs melanoma cells to deregulate mitochondrial metabolism, to accumulate reduced species (NADH), and to centralize metabolism in the cytosol. The aim of this work was to study the effect of gene silencing in malignant melanoma A375 cells on metabolic processes in cytosol and mitochondria. Gene silencing of HIF-1 $\alpha$, and miR-210 in normoxia and pseudohypoxia, and analysis of its effect on MITF-M, and PDHA1 expression. Detection of cytosolic NADH by Peredox-mCherry Assay. Detection of OCR, and ECAR using Seahorse XF96. Measurement of produced $\mathrm{O}_{2}{ }^{-}$with MitoTracker Red CMXRos. ${ }^{1} \mathrm{H}$ NMR analysis of metabolites present in cell suspension, and medium. By gene silencing of HIF-1 $\alpha$ and miR-210 the expression of PDHA1 was upregulated while that of MITF-M was downregulated, yielding acceleration of mitochondrial respiratory activity and thus elimination of ROS. Hence, we detected a significantly reduced A375 cell viability, an increase in alanine, inositol, nucleotides, and other metabolites that together define apoptosis. Based on the results of measurements of mitochondrial resipiratory activity, ROS production, and changes in the metabolites obtained in cells under the observed conditions, we concluded that silencing of HIF-1 $\alpha$ and miR-210 yields apoptosis and, ultimately, apoptotic cell death in A375 melanoma cells.

Over the last two decades the scientific community has been focused on the hypoxic microenvironment of tumours. Hypoxia-inducible factor signalling pathway (HIF-signalling) is described for different tissues such as brain $^{1,2}$, lungs ${ }^{3,4}$, cardio-vascular system ${ }^{5,6}$, muscles $^{7-9}$ or skin $^{10-14}$. In the given tissues, HIF-signalling has a different priority compared to the rest of the affected growth, metabolic and transcription pathways ${ }^{15-18}$. In the case of malignant melanoma (MM) the HIF-signalling pathway is one of the most dominant pathways ${ }^{11,19,20}$. Malignant melanoma is an oncological skin disease, the presentation of which increases in populations living in temperate climate areas and is connected to pigmentation as well as thicknesses of the skin, high dose of UV radiation and positive family history for $\mathrm{MM}^{21-25}$. Malignant melanoma is one of the most aggressive malignancies ${ }^{26}$. The epidemiology of malignant melanoma in Europe is based on three main factors; age (over 40 y), male gender, and location (head/neck, trunk, upper and lower extremity) ${ }^{27-30}$. The incidence of MM in Europe is increasing at a rate of $3-7 \%, 144,000$ new cases per year, and 27,000 deaths per year ${ }^{31}$. This disease has relatively fast slope because it often takes only six to nine months from late diagnosis to patient's death ${ }^{32}$.

\footnotetext{
${ }^{1}$ Department of Medical and Clinical Biochemistry, Faculty of Medicine, Pavol Jozef Šafárik University in Košice, Trieda SNP 1, 04011 Košice, Slovakia. ${ }^{2}$ Department of Biology, Faculty of Medicine, Pavol Jozef Šafárik University in Košice, Košice, Slovakia. ${ }^{3}$ Gottfried Schatz Research Center for Cell Signaling, Metabolism and Aging Molecular Biology and Biochemistry, Medical University of Graz, Graz, Austria. ${ }^{4 B i o T e c h M e d, ~ G r a z, ~ A u s t r i a . ~}{ }^{\square}$ email: miroslava.rabajdova@upjs.sk
} 

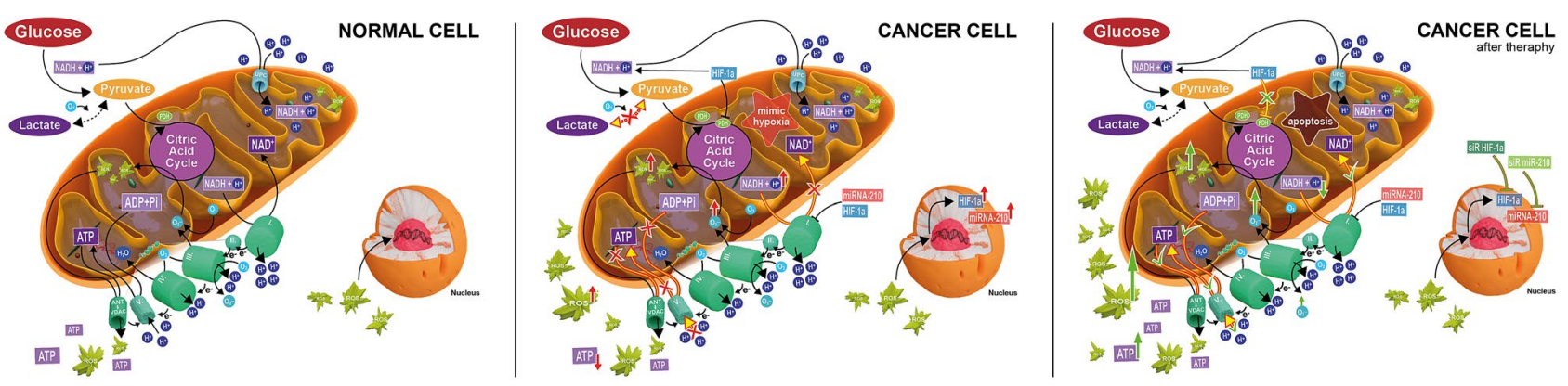

Figure 1. Mitochondria; normal cell: ROS is produced naturally, this ROS are deactivated by the anti-oxidation activity of enzymes as SOD which expression is stimulated; cancer cell: due mimic hypoxia cells uncouple the OXPHOS, accumulate NADH, increase ROS and activate expression of hypoxic survival genes as HIF-1 $\alpha$ and miR-210; cancer cell after gene-therapy: due to gene silencing of HIF-1 $\alpha$ and miR-210, the cancer cells lead to apoptosis because of re-activating of OXPHOS, increase in ROS and secreting of apoptic molecules.

Hypoxia-inducibile factor $1 \alpha$ signaling pathway (HIF-1 $\alpha$ ) is hyperactivated in long-term anoxia conditions ${ }^{33}$ and even at physiological $\mathrm{O}_{2}$ concentration and induces pseudohypoxic conditions in the cell, increases oxidative stress, and ROS production. Due to BRAF (V-raf murine sarcoma viral oncogenes homolog B1) mutations cells increase activation of MEK pathway (p38/p38y) in an effort to ensure sufficient oxygen supply $\left(\mathrm{O}_{2}\right)$. A major activator of MAPK/ERK kinase, the so-called MEK (MAPK-Mitogen-activated protein kinase; ERKExtracellular-signal-regulated kinase), is BRAF. The mutation of the BRAF gene, referred to as BRAF ${ }^{\mathrm{V} 600 \mathrm{E}}$, is $90 \%$ of the $\mathrm{T}$ to $\mathrm{A}$ switch at the 1799th position of exon 15, replacement of the amino acid valine with glutamic acid at position 600 in the protein residue $e^{34}$. The BRAF activating mutations occur in about $50 \%$ of the cutaneous melanomas with BRAF ${ }^{\mathrm{V} 600 \mathrm{E}}$ being the most frequent variant ${ }^{35}$. Furthermore, the activity of transcription factors (eg. MITF-Microphthalmia-associated transcription factor; a regulator of melanocyte development and a key melanogenesis factor) that are capable of independently producing growth and regulatory signals (TFEB and TFE3 regulating lysosomal activity and autophagy) is increased ${ }^{34,36}$ and gather up the energy metabolism in the cytosol (glycolysis) ${ }^{37}$. Under physiological conditions the MAPK pathway decreases MITF activity by ubiquitindependent proteolysis. However, due to reciprocal p38 phosphorylation the MEK cascade can promote MITF expression leading to melanocyte differentiation and onco-melanogenesis ${ }^{38}$. Overexpression of MITF is associated with a negative progression of melanoma disease. Increased MITF gene amplification was detected in $10 \%$ of primary cutaneous melanoma and $15-20 \%$ of metastatic melanomas ${ }^{39}$.

Our aim was to study metabolic (glycolysis, mitochondrial viability, metabolite accumulation) and genetic effects (MITF-M, PDHA1 expression) due to hypoxa-miR miR-210, and HIF-1a silencing. Our measurements support the theory of pro-apoptotic signal induction in targeted silencing of hypoxic factors. The present study suggests that by attenuating the action of hypoxamir miR-210 or HIF-1 $\alpha$, mitochondrial respiration acceleration is achieved, thereby releasing ROS and subsequently labeling the cell for self-destruction. Thus, a more thorough investigation of mitochondrial activity in MM cells can be a key for development of organelle targeting therapy.

Formation of ROS by pigment cells. It is well known that mitochondria (especially respiratory complex I in inner membrane) play an irreplaceable role in cell proliferation, calcium signaling modulation, and ROS production which serve as signaling molecules in downstream cell cycle control pathways such as apoptosis ${ }^{40}$. Isolated complex I deficiency is a very common cause of mitochondrial disorders that lead to a wide range of diseases ${ }^{41}$. Mitochondrial disorders are associated with mutations in the genes encoding complex I subunits and repair factors are in turn associated with an increase in ROS (Fig. 1$)^{42}$.

Cells with insufficient respiratory chain activity are well resistant to mitochondrial stress and endoplasmic reticulum (ER) stress. In contrast, cells with active respiratory chain complexes but without the ability to generate electron flux are resistant to mitochondrial stress but sensitive to ER stress. Cells with partial electron flux reduction are sensitive to apoptotic signals from both organelles ${ }^{42}$. The resistance of cancer cells to apoptotic signals is attributed to the increased concentration of substrate NADH for the Complex I due to respiratory complex dysfunction ${ }^{43,44}$.

Production of ROS $\left(\mathrm{H}_{2} \mathrm{O}_{2}, \mathrm{O}_{2}{ }^{--}\right.$, and others) in subcellular structures is mainly located in microsomes (45\%), peroxisomes (35\%), mitochondria (15\%), and in cytosol by specific enzymes $(5 \%)^{45}$. The production of ROS in cell substructures is stable under physiological conditions. Approximately half of the total amount of hydrogen peroxide produced in mitochondria is generated by respiratory complexes I and III, whereas complex I generates up to $70 \%$ of $\operatorname{ROS}^{45}$. The second half of the total amount of ROS produced by mitochondria comes from metabolic processes of enzymes dissolved in the mitochondrial matrix, mainly dihydrolipoamide dehydrogenase (DLDH) and from submitochondrial particles (SMP) ${ }^{45}$.

In an attempt to compensate for the excessive accumulation of $\mathrm{NADH}$, mitochondria utilize the present $\mathrm{O}_{2}$ in complex I to re-oxidize $\mathrm{NADH}$, which leads to the formation of $\mathrm{NAD}^{+}, \mathrm{H}^{+}$and $\mathrm{O}_{2}{ }^{-{ }^{-}}$followed by $\mathrm{H}_{2} \mathrm{O}_{2}{ }^{42}$. According to one of the theories, complex I is inhibited by high NADH concentration suggesting that NADH can bind to an unconventional allosteric site changing the redox potential and $\mathrm{O}_{2}$ availability ${ }^{45}$. As a result, hydrogen peroxide formed by complex III accumulates in the mitochondrial matrix, intermembrane space (IMS), and cytosol of cancer cells ${ }^{45-47}$. 


\begin{tabular}{|c|c|c|c|c|c|}
\hline & \multicolumn{3}{|c|}{ Normoxia siR neg cont } & \multicolumn{2}{|c|}{ Hypoxia siR neg cont } \\
\hline & siR HIF-1 $\alpha$ & siR miR-210 & siR neg cont (hypoxia) & siR HIF-1 $\alpha$ & siR miR-210 \\
\hline MITF-M & $\downarrow 56 \%$ & $\downarrow 28 \%$ & $\downarrow 28 \%$ & $\downarrow 33 \%$ & $\downarrow 59 \%$ \\
\hline PDHA1 & $\downarrow 39 \%$ & $\uparrow 14 \%$ & $\downarrow 14 \%$ & $\uparrow 4 \%$ & $\uparrow 8 \%$ \\
\hline HIF- $1 a$ & $\uparrow 10 \%$ & $\downarrow 2 \%$ & $\downarrow 33 \%$ & $\downarrow 33 \%$ & $\downarrow 13 \%$ \\
\hline miR-210 & $\uparrow 12 \%$ & $\downarrow 30 \%$ & $\downarrow 3 \%$ & $\downarrow 30 \%$ & $\downarrow 59 \%$ \\
\hline
\end{tabular}

Table 1. Comparison of the relative expression values to siR neg cont in normoxia for siR HIF-1a and siR miR-210 and comparison of the relative expression values to siR neg cont in hypoxia for siR HIF-1 $\alpha$ and siR miR-210 in hypoxia.

Energy metabolism of melanoma cells. The activity of OXPHOS (oxidative phosphorylation) is dependent on $\mathrm{NADH}+\mathrm{H}^{+}$and $\mathrm{FADH}_{2}$ produced in the citrate cycle, the activity of which is controlled by the pyruvate dehydrogenase complex (PDC-pyruvate dehydroganase, dihydrolipoamide acetyltransferase and dihydrolipoamide dehydrogenase $)^{48}$. The oxidative decarboxylation of pyruvate to Acetyl-CoA, $\mathrm{CO}_{2}$, and $\mathrm{NADH}$ catalyzed by PDC links glycolysis in the cytosol to the citrate cycle cell in mitochondria. Aberrant HIF-1 $\alpha$ expression affects the disconnection of OXPHOS from energy generation, and cells preferentially utilize glycolysis. Malignant melanoma (MM) tumour cells are described as glycolytic hypoxic cells ${ }^{49}$ and overexpress HIF-1 $\alpha$ in an attempt to de novo vascularization (upregulation of VEGF) and thereby compensate for $\mathrm{O}_{2}$ deficiency ${ }^{50}$.

Cells suffering from hypoxia (pseudohypoxia) due to decreased activity of respiratory complex I and/or due to mutation of the NADH-transdehydrogenase subunit leads to accumulation of NADH $\left(\mathrm{NADPH}+\mathrm{NAD}^{+} \leftrightarrow \mathrm{NADP}^{+}+\mathrm{NADH}\right)$ which slows down and stops the citrate cycle and thus disconnects $\mathrm{OXPHOS}^{51}$. In melanoma cells, ROS production increases due to inactive OXPHOS ${ }^{52,53}$, whereas the lack of $\mathrm{O}_{2}$ associated with reduced $\mathrm{NADH}$ transformation into $\mathrm{NAD}^{+}$leads to pseudohypoxia ${ }^{45}$. These are contradictory events resulting from damage to the respiratory chain complex $\mathrm{I}^{51}$. Complex I mutations inactivating NADHubiquinone subunits and other molecules of $\mathrm{O}_{2}$ responsible for $\mathrm{O}_{2}{ }^{-}$generation may be so destructive that cells reduce ROS production by the complex $\mathrm{I}^{54}$. Complex I mutations may therefore act as an accelerator of tumour progression due to ROS release, as well as negatively affect disease progression due to complex I disintegration.

Hypoxa-miR miR-210 stabilizes HIF-1a by inactivating the HIF-1 $\alpha$-inhibitor GPD1L (glycerol-3-phosphate dehydrogenase 1-like ${ }^{55,56}$. miR-210 negatively affects the activity of ISCU electron transporters in respiratory complex I and is thus largely involved in the inactivation of OXPHOS, and subsequent accumulation of NADH and ROS in the mitochondrial matrix and IMS ${ }^{57,58}$. HIF-1 $\alpha$, as a major regulator of adaptation to hypoxic conditions, alters the expression of PGC-1 $1 \alpha$ (peroxisome proliferator-activated receptor- $\gamma$ coactivator $1 \alpha$ ) to stimulate mitochondrial biogenesis ${ }^{59}$. Induction of HIF-1 $\alpha$-dependent genes on PGC-1 $\alpha$ stimulus under normoxic conditions is a cell response to stabilization of HIF-1 $\alpha$ by miR- $210^{60}$.

MITF adjusts the expression of 'OXPHOS genes' by directly influencing mitochondrial regulators (e.g. as PGC-1 $\alpha$ ) and MITF also influences $\mathrm{PDH}^{48}$ by negative regulation of expression of the genes encoding vacuolar $\mathrm{H}^{+}$-ATPase subunits (v-ATPase) ${ }^{61}$ which results in proton accumulation in IMS and the lowering of $\mathrm{pH}$. MITF in lysosomal $\mathrm{pH}$-homeostasis regulates melanin formation ${ }^{62}$ in melanosomes (lysosome-like organelles) and its distribution to keratinocytes. Defective melanin results in cancer melanogenesis in amelanotic cells along with an increase in HIF-1 $\alpha$ expression ${ }^{63}$. Stress-induced autophagy (lack of nutrients, hypoxia, ROS, and others) regulated by MITF factors promotes proteosynthesis and lipogenesis for subsequent proteolysis and $\beta$-oxidation of fatty acids, thereby generating ATP by OXPHOS for melanoma cell survival ${ }^{36}$, and at the same time a high level of NADH inhibits this process resulting in the dominance of glycolysis as the main energy pathway of the melanoma cell ${ }^{64}$.

\section{Results}

Gene expression. By RT-PCR analysis we detected changes in the target gene expression. Cells affected with siR HIF-1a were manifested with 56\% decrease in MITF-M and 39\% decrease in PDHA1 compared to siR neg cont cells in normoxia and 33\% decrease in MITF-M, and 4\% increase in PDHA1 compared to siR neg cont cells in hypoxia. Cells affected with siR miR-210 were presented with $28 \%$ decrease in MITF-M, and $14 \%$ increase in PDHA1 compared to siR neg cont cells in normoxia and 59\% decrease in MITF-M, and 8\% increase in PDHA1 compared to siR neg cont cells in hypoxia.

The evaluation of gene expression in the relationship between experimental groups in normoxia and hypoxia, and in the relationship between individual genes in the experimental group is gathered in Table 1 and Fig. 2 (see more in supplemetary ST 2).

Peredox-mCherry T-Sapphire Assay. The production of NADH by MM A375 cells under normoxic and pseudohypoxic conditions was approximately at the same level and a slight increase of $\pm 7 \%$ was observed in the control cells in induced hypoxia. We detected a significant reduction of the free $\mathrm{NADH} / \mathrm{NAD}{ }^{+}$ratio in normoxia by $\pm 37 \%(P=0.0031)$ after HIF-1 $\alpha$ silencing, and in miR-210 by $\pm 50 \%(P<0.0001)$. An increase in the free NADH/NAD ${ }^{+}$ratio in pseudohypoxia after silencing of HIF-1 $\alpha$ by $\pm 15 \%(P=0.0439)$, and in miR-210 by $\pm 9 \%(P=0.2501)$ was found compared to the control in normoxia (Fig. 3, supplementary data ST 3$)$. 

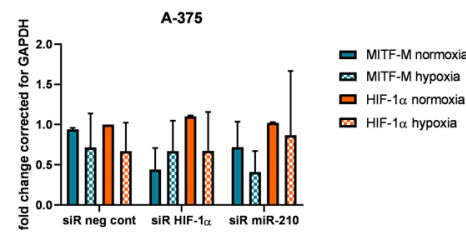

四 HIF-1 1 hypoxia
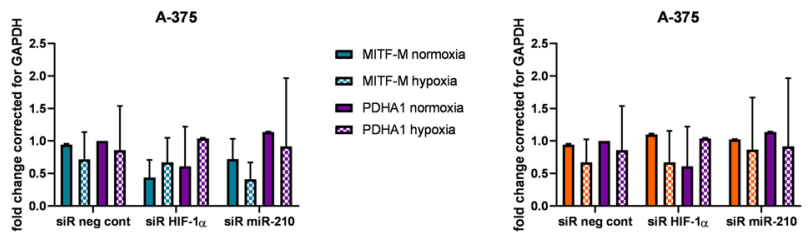

口 HIF-1 $\alpha$ normoxia

HF-11 hypoxia

DDHA1 normox
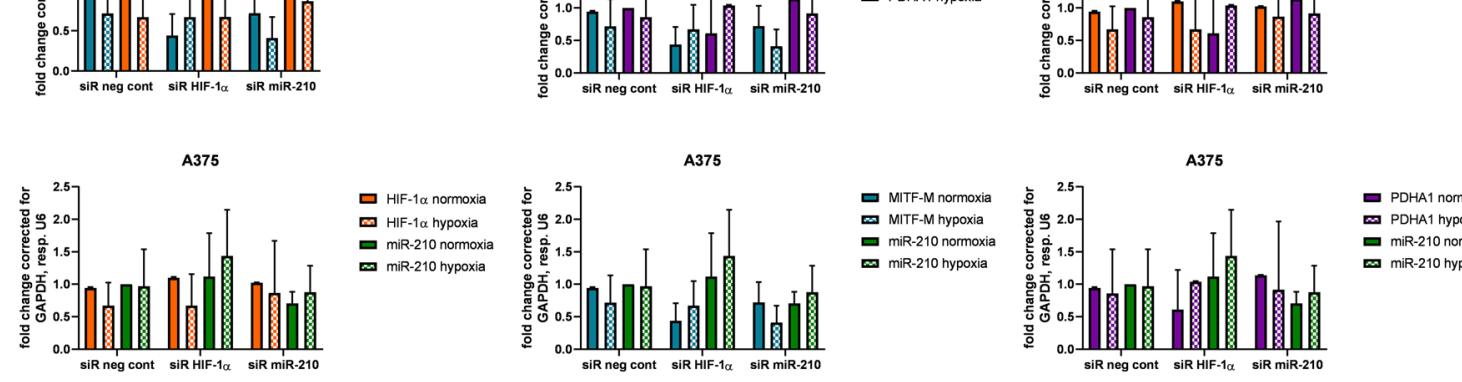

- PDHA1 normoxia

PDHA1 hypoxia

a miR-210 normoxia

Figure 2. Relative gene expression of HIF-1 $\alpha$, miR-210, MITF-M, PDHA1 in normoxia and hypoxia of siR neg cont cells, siR HIF-1 $\alpha$, siR miR-210 (significant change with $P$ value $<0.05$ marked with ${ }^{\star}, P$ value $<0.01$ marked with ${ }^{\star *}, P$ value $<0.001$ marked with $\left.{ }^{\star * *}\right)$. Relative expression values were analysed by REST Software (Qiagen).

A-375

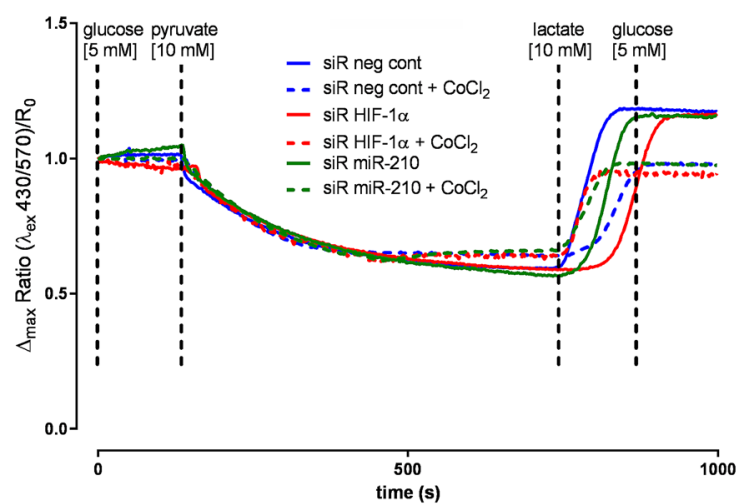

A375 absolute value

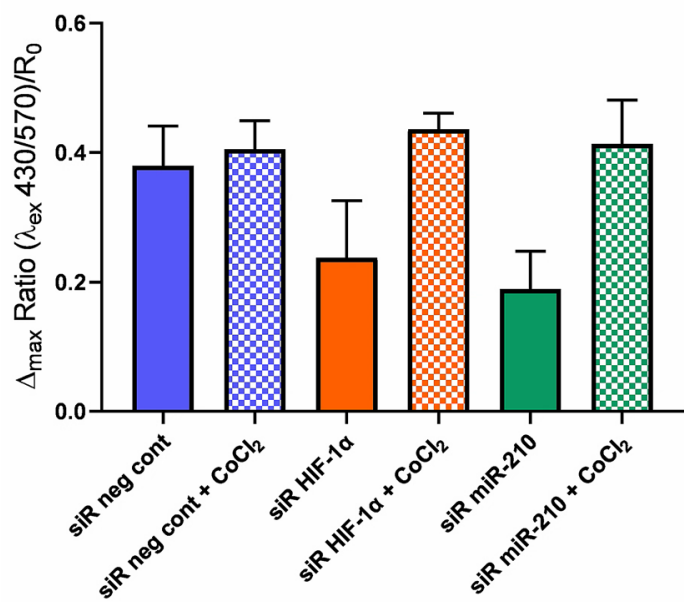

A-375
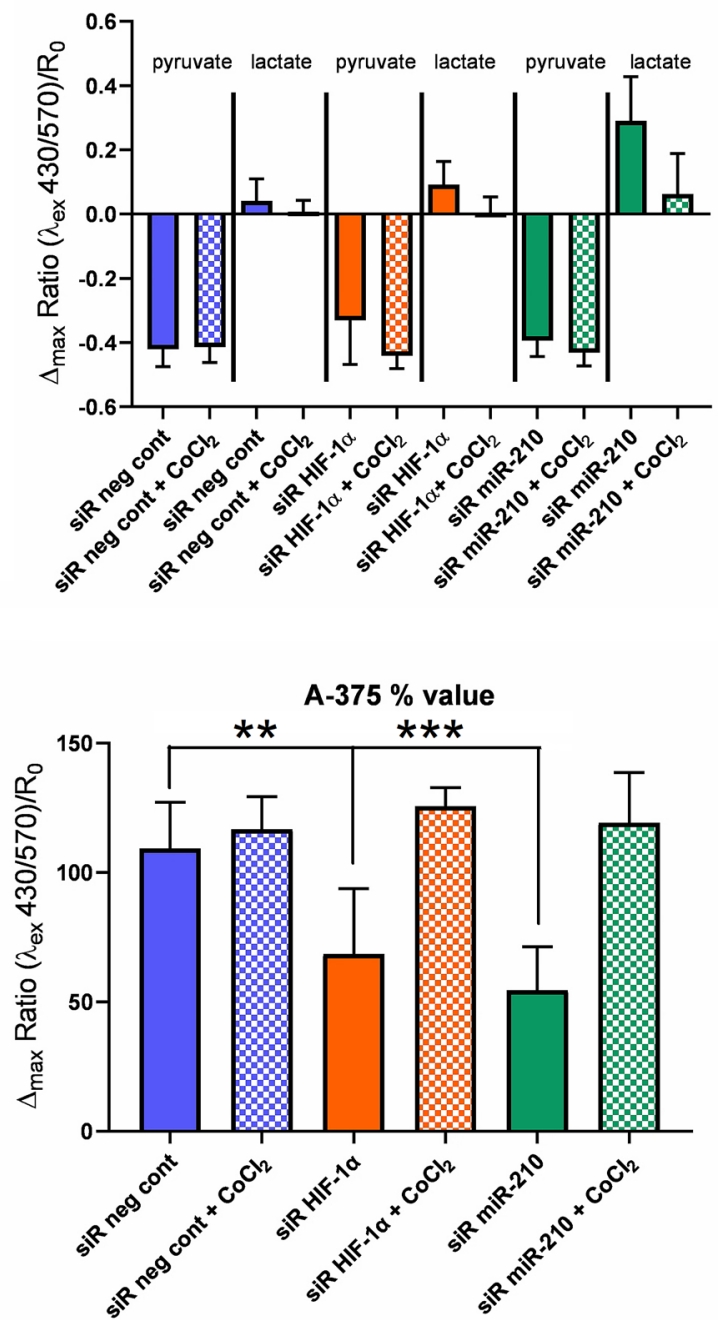

Figure 3. Cytosolic $\mathrm{NADH} / \mathrm{NAD}^{+}$ratio; the level of free $\mathrm{NADH}$ decreased in normoxia and slightly decreased in hypoxia (significant change with $P$ value $<0.05$ marked with ${ }^{\star}, P$ value $<0.01$ marked with ${ }^{\star *}, P$ value $<0.001$ marked with ${ }^{\star * *}$ ). 
A

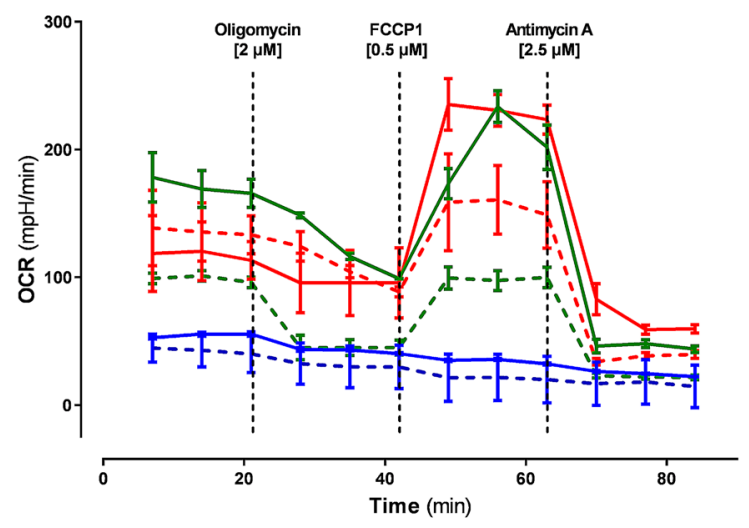

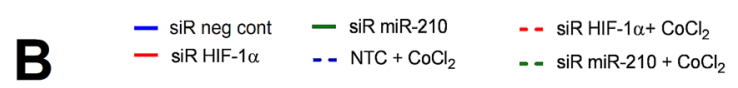

A-375

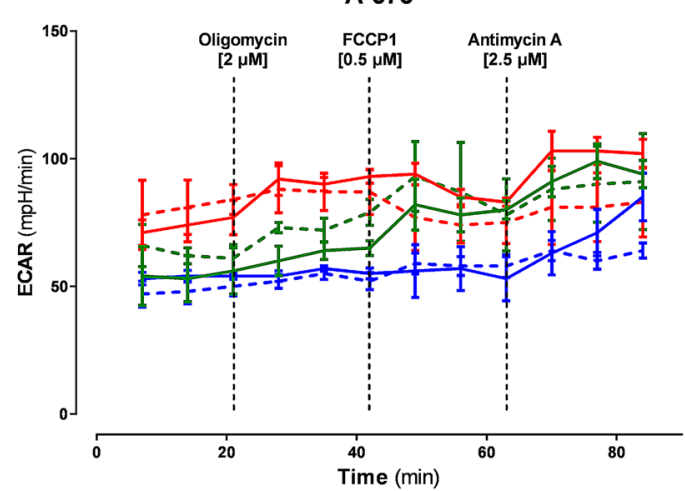

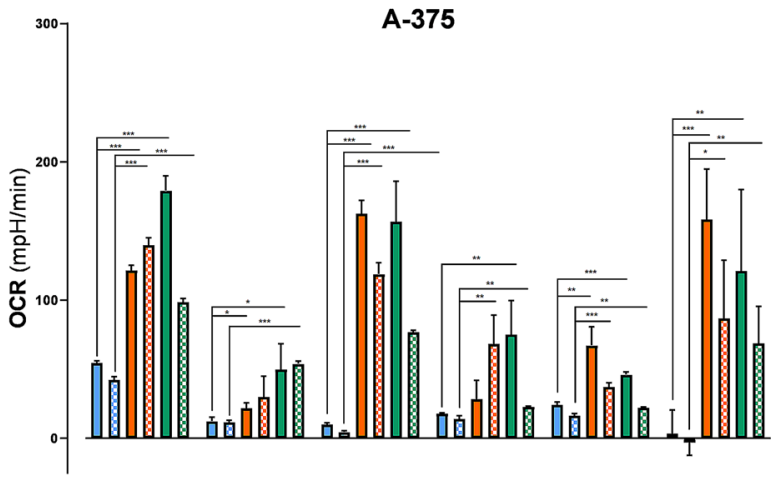

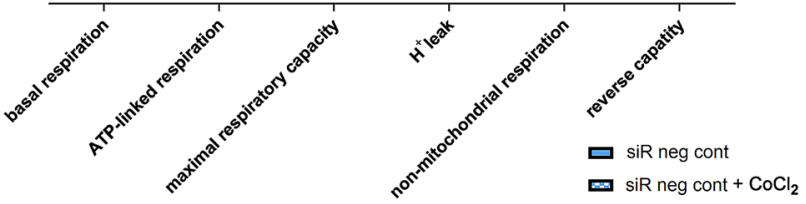

siR neg cont

口 siR HIF-1a

siR $\mathrm{HIF}-1 \alpha+\mathrm{CoCl}_{2}$

口 siR miR-210

siR miR-210 $+\mathrm{CoCl}_{2}$

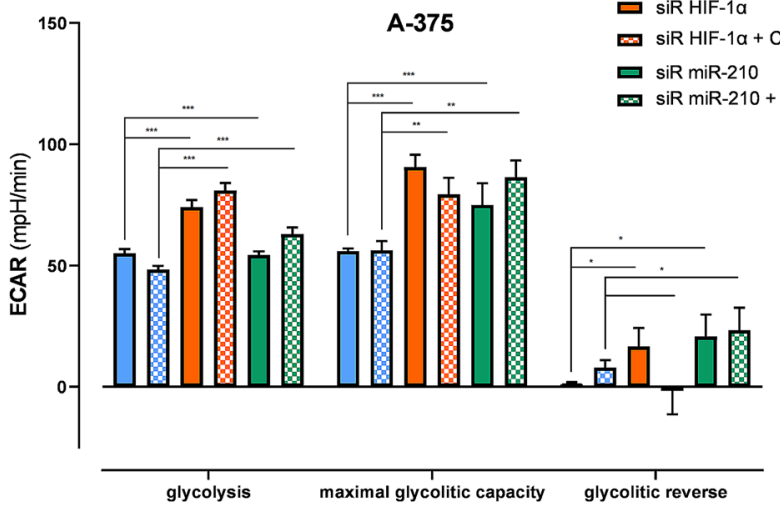

Figure 4. Oxygen consumption rate and extracellular acidification rate; mitochondria viability (basal respiration, ATP production, reverse capacity) of malignant melanoma cells was boosted after gene silencing (HIF-1 $\alpha$, miR-210) in normoxia as well as in hypoxia (significant change with $P$ value $<0.05$ marked with ${ }^{\star}, P$ value $<0.01$ marked with ${ }^{\star *}, P$ value $<0.001$ marked with $\left.{ }^{\star * *}\right)$.

\begin{tabular}{|l|l|l|l|l|l|}
\hline & \multicolumn{3}{|l|}{ Normoxia siR neg cont } & \multicolumn{2}{l|}{ Hypoxia siR neg cont } \\
\cline { 2 - 6 } & siR HIF- $1 \boldsymbol{\alpha}$ & siR miR-210 & siR neg cont (hypoxia) & siR HIF-1a & siR miR-210 \\
\hline Basal respiration & $\uparrow 111 \%$ & $\uparrow 210 \%$ & $\downarrow 25 \%$ & $\uparrow 144 \%$ & $\uparrow 81 \%$ \\
\hline v-ATPase & $\uparrow 76 \%$ & $\uparrow 302 \%$ & $\downarrow 5 \%$ & $\uparrow 142 \%$ & $\uparrow 335 \%$ \\
\hline Maximal respiration capacity & $\uparrow 1529 \%$ & $\uparrow 1471 \%$ & $\downarrow 55 \%$ & $\uparrow 1090 \%$ & $\uparrow 668 \%$ \\
\hline $\mathrm{H}^{+}$leak & $\uparrow 58 \%$ & $\uparrow 319 \%$ & $\downarrow 21 \%$ & $\uparrow 282 \%$ & $\uparrow 27 \%$ \\
\hline Non-mitochondrial respiration & $\uparrow 176 \%$ & $\uparrow 89 \%$ & $\uparrow 16 \%$ & $\uparrow 53 \%$ & $\downarrow 9 \%$ \\
\hline Reverse capacity & $\uparrow 4427 \%$ & $\uparrow 3364 \%$ & $\downarrow 15 \%$ & $\uparrow 2384 \%$ & $\uparrow 1866 \%$ \\
\hline
\end{tabular}

Table 2. Comparison of the OCR values to siR neg cont in normoxia for siR HIF-1 $\alpha$ and siR miR-210. Comparison of the OCR values to siR neg cont in hypoxia for siR HIF-1a and siR miR-210 in hypoxia.

Seahorse assay. Determination of mitochondrial viability from OCR measurements according to Seahorse Assay recommendations ${ }^{65}$ (Fig. 4A, Table 2, supplementary data ST 4). From analysis of ECAR measurements according to the recommendations of the Seahorse Assay ${ }^{65}$ (Fig. 4B, Table 3, supplementary data ST 5).

MitoTracker Red CMXRos assay. In terms of $\mathrm{O}_{2}{ }^{--}$production and accumulation in mitochondria (Fig. 5, supplementary data ST 6 ), we observed a decrease in ROS molecules by $\pm 15 \%$ in hypoxia. After HIF- $1 a$ gene silencing the production of $\mathrm{O}_{2}{ }^{--}$increased by $\pm 87 \%$ in normoxia, and by $\pm 37 \%$ in hypoxia compared to normoxia control. We observed a more significant increase in ROS $\pm 115 \%$ after silencing of miR-210 in normoxia, and by $\pm 41 \%$ in hypoxia compared to the control group in normoxia. 


\begin{tabular}{|l|l|l|l|l|l|}
\hline \multirow{2}{*}{} & \multicolumn{2}{|l|}{ Normoxia siR neg cont } & \multicolumn{2}{l|}{ Hypoxia siR neg cont } \\
\cline { 2 - 6 } & siR HIF-1a & siR miR-210 & siR neg cont (hypoxia) & siR HIF-1a & siR miR-210 \\
\hline Glycolysis & $\uparrow 17 \%$ & $\downarrow 14 \%$ & $\downarrow 24 \%$ & $\uparrow 28 \%$ & $\downarrow 13 \%$ \\
\hline Glycolytic capacity & $\uparrow 5 \%$ & $\downarrow 14 \%$ & $\downarrow 35 \%$ & $\uparrow 9 \%$ & $\downarrow 36 \%$ \\
\hline Glycolysis reserve & $\uparrow 1566 \%$ & $\uparrow 1966 \%$ & $\downarrow 800 \%$ & $\uparrow 66 \%$ & $\uparrow 2233 \%$ \\
\hline
\end{tabular}

Table 3. Comparison of the ECAR values to siR neg cont in normoxia for siR HIF-1a and siR miR-210. Comparison of the ECAR values to siR neg cont in hypoxia for siR HIF-1 $\alpha$ and siR miR-210 in hypoxia.

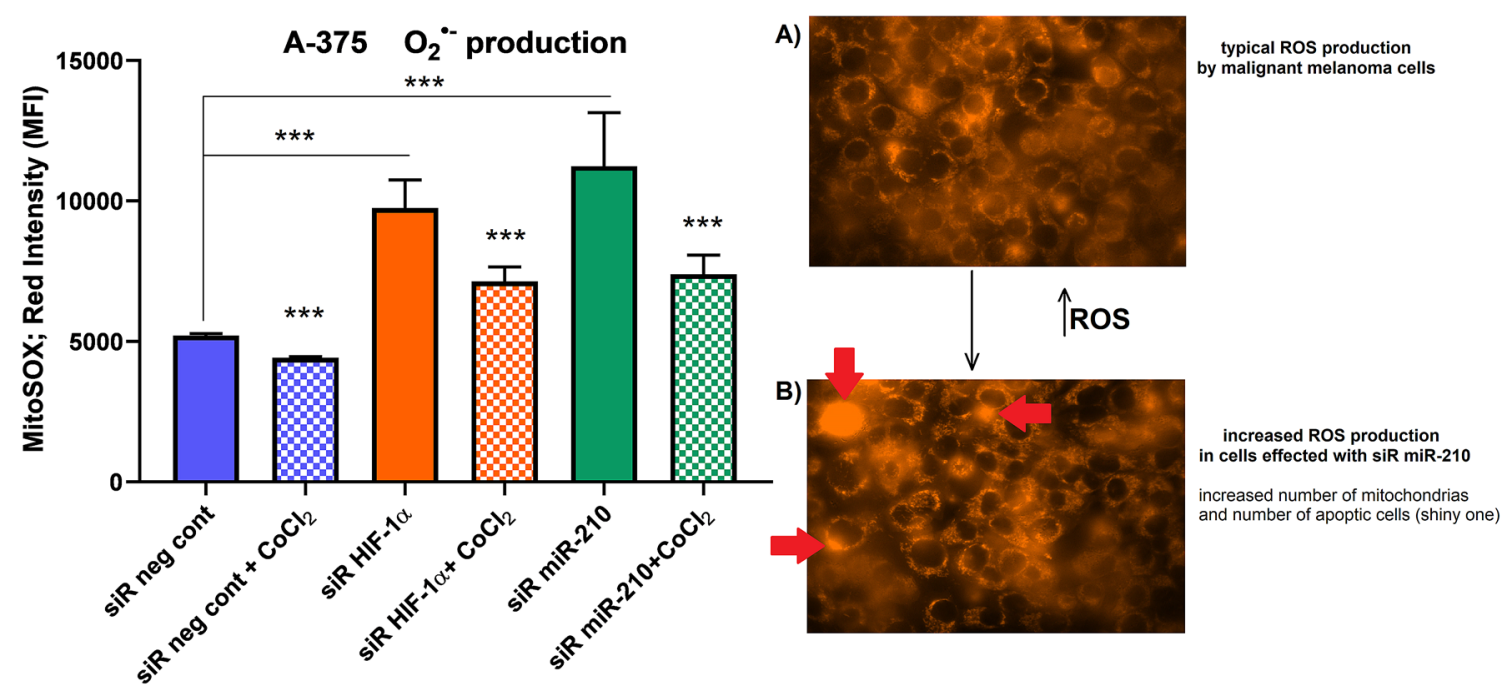

Figure 5. ROS production: box-plot describes changes in the ROS level in A375 cells in normoxia and hypoxia (blue: siR neg cont in normoxia, blue squared: siR neg cont in hypoxia, orange: gene silencing of HIF-1 $\alpha$ in normoxia, orange squared: gene silencing of HIF-1a in hypoxia, green: gene silencing of miR-210 in normoxia, green squared: gene silencing of miR-210 in hypoxia). (A) A375 cells in hypoxia (intensity of the "red light" depends on ROS production); (B) A375 cells after gene silencing of miR-210 in hypoxia (red arrows target apoptic cells). Analysed by VisiView acquisition software (Universal Imaging, Visitron Systems).

1D ${ }^{1} \mathrm{H}$ NMR. Predictive component analysis (PCA) score plots analysis was used to identify differences in metabolite representation between the analyzed siRNA negative control (siR neg cont) and siR HIF-1 $\alpha$ groups, siR neg cont and siR miR-210, or siR HIF- $1 \alpha$ and siR miR-210, respectively (Fig. 6A-C, Table 4). Identification of represented metabolites, their levels and loading plots were obtained from PCA analysis (Fig. 6D-F). In the analyzed groups we observed significant changes in the level of metabolites, their up- and down-regulation, see Table 5.

PCA score plot of siR neg cont and siRNA HIF-1 1 cell A375 samples was obtained using one predictive and four orthogonal components, with PC1 of 59.02\% and PC2 of $24.69 \%$. OPLS-DA score plot of siR neg cont and siRNA miR-210 samples using one predictive and four orthogonal components, with PC1 of $64.89 \%$ and PC2 of $20.24 \%$. And of HIF- $1 \alpha$ and siRNA miR-210 cell A375 samples using one predictive and four orthogonal components, with PC1 of $56.56 \%$ and PC2 of $27.81 \%$.

Cell viability. Cell viability test by the Tryptan Blue experiment exhibited inhibition of cell proliferation for melanoma A375 cells after HIF-1a and miR-210 gene silencing but not for siR neg cont melanoma cells in normoxia nor hypoxia. Hypoxic conditions did not affect cell viability (Fig. 7). Our present study indentified a key miRNA similar to HIFs which inhibition could induce apoptosis or apoptosis-like cell death.

By analyzing the growth curves of the experimental groups, we can observe that A-375 cells affected by HIF-1a siRNA, and miR-210 siRNA had a significantly lower number of cells at $72 \mathrm{~h}$ compared to siR neg cont in normoxia as well as in hypoxia. By analogy, we detected a trend in the growth of "dead" cells. We observed a significant increase in the experimental group after silencing of the HIF-1 $\alpha$, and miR-210 genes compared to siR neg cont in both oxygen conditions. Gene silencing to siR neg cont significantly reduced the viability of A-375 melanoma cells in both normoxia and hypoxia. We detected an insignificant change in viability when comparing siR neg cont in normoxia and hypoxia (Fig. 7, supplementary data ST 7). 
PCA

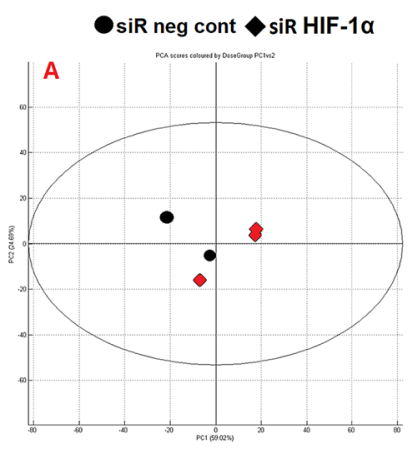

-siR neg cont $\star$ siR miR-210

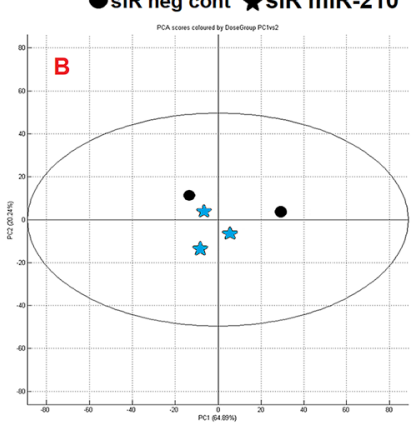

$\downarrow$ siR HIF-1a $\star$ siR miR-210

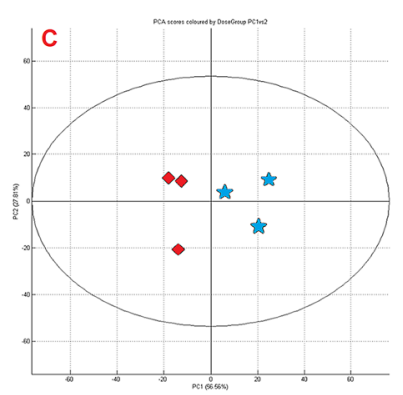

Reduced spectrum
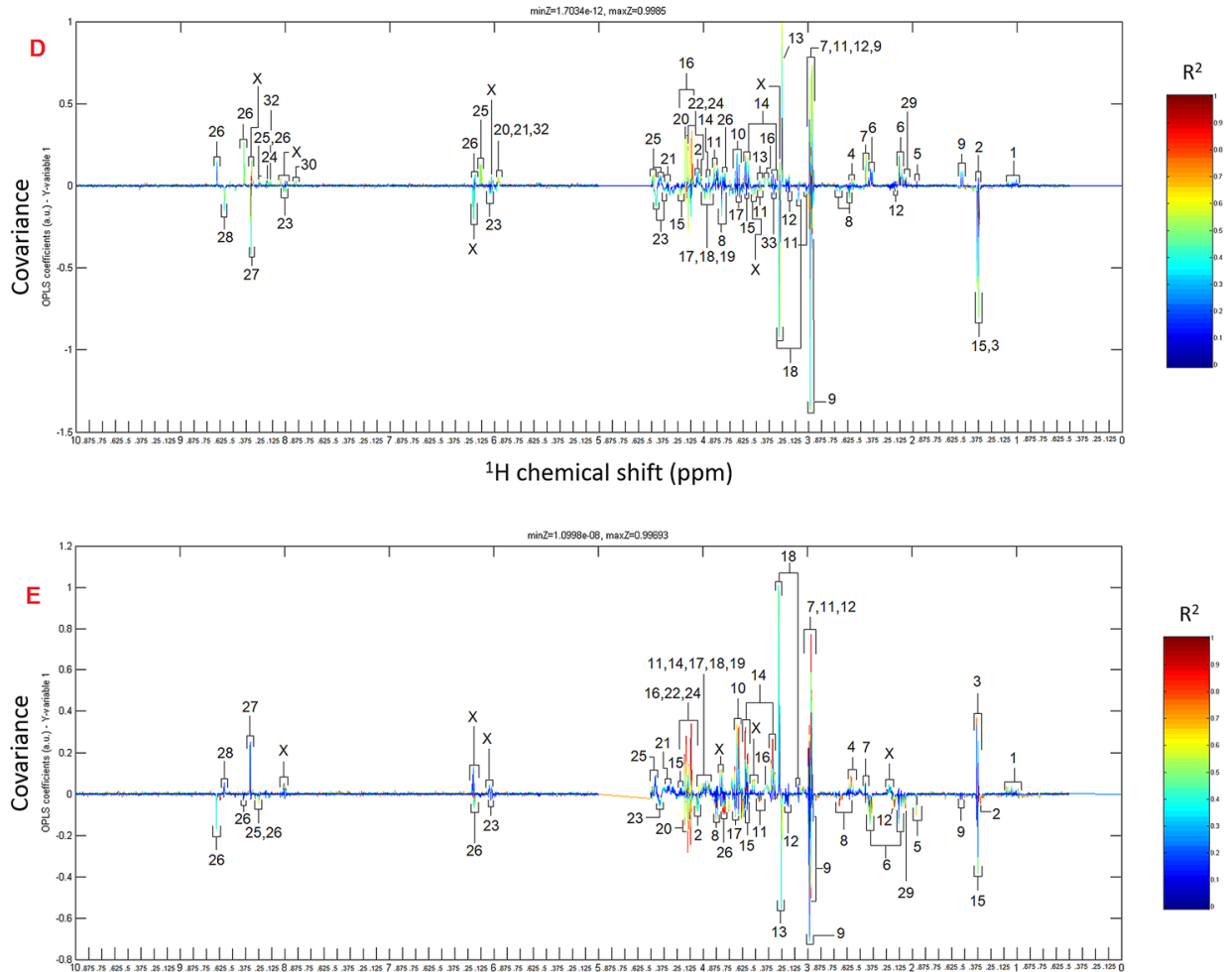

${ }^{1} \mathrm{H}$ chemical shift (ppm)

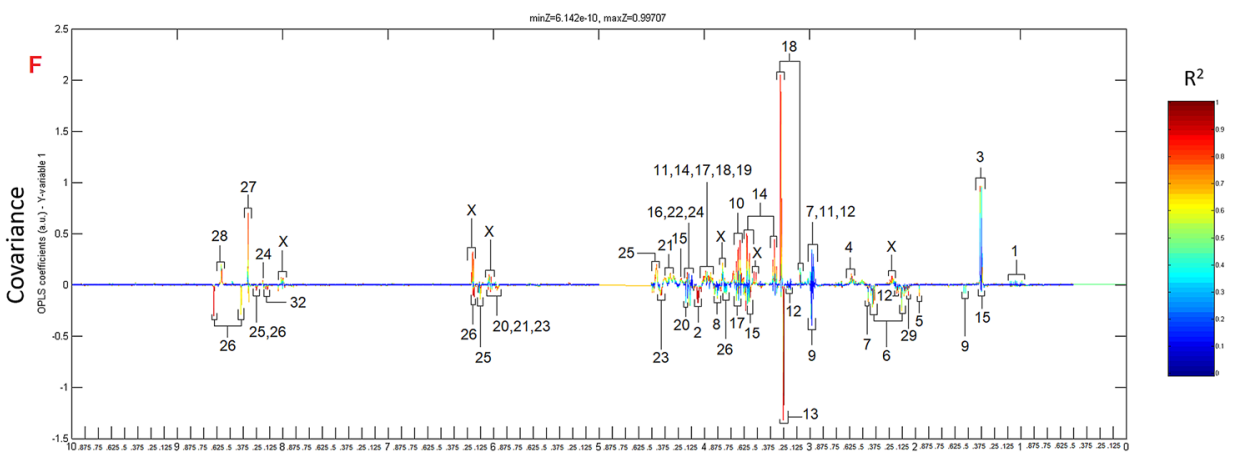

${ }^{1} \mathrm{H}$ chemical shift (ppm)

Figure 6. PCA model between the groups (A) siR neg cont and siR HIF-1 $\alpha$, (B) siR neg cont and siR miR-210, (C) siR HIF- $1 \alpha$ and siR miR-210; ${ }^{1} \mathrm{H}$ NMR spectra colour map of metabolite significance variations between the groups, (D) siR neg cont and siR HIF-1a, (E) siR neg cont and siR miR-210, (F) siR HIF-1a and siR miR210. Peak in positive direction indicates the increased level of metabolite, peak in negative direction indicates decreased level of metabolite (X-undefined metabolite). Analysed by Bruker Topspin 3.1 and MestReNova 10.0 software (Mestrelab Research, Santiago de Compostela, Spain).

\section{Discussion}

By suppressing the expression of miR-210 we wanted to introduce metabolic changes comparable with suppressing HIF-1a transcription factor similar to our previously reported study on malignant melanoma cell line SKMEL- $30^{66}$. Both conditions yielded reduction in the MITF-M expression and increase in the PDHA1 expression, which are reflected in the change of cell metabolism. It is well known that increased PDHA1 activity inhibits the Warburg effect and induces apoptosis ${ }^{67}$.

Our goal was to induce conditions that would minimize this effect. We detected slightly reduced MITF-M expression by HIF-1 1 gene silencing and a similar effect was observed by attenuating miR-210. We detected an increase in PDHA1 gene expression activity and at the same time a decrease in MITF-M expression activity by gene silencing of HIF-1 $\alpha$ as well as miR-210. This effect elicited in regulatory gene pathways was reflected in mitochondrial activity and stimulation of pro-apoptotic signals. HIF-1 a positively affects MITF-M expression under hypoxic conditions ${ }^{48,68}$. Increased activation of HIF-1 $\alpha$ leads to MITF-M hyperactivation which negatively 


\begin{tabular}{|l|l|l|l|l|l|}
\hline Number & Metabolite & Number & Metabolite & Number & Metabolite \\
\hline 1 & Gal, Ile, Leu & 12 & Choline & 23 & NAD $^{+}$ \\
\hline 2 & Lactate & 13 & Carnitine & 24 & NADH \\
\hline 3 & Ala & 14 & Myoinositol & 25 & ATP \\
\hline 4 & DNA & 15 & Thr & 26 & AMP, adenine \\
\hline 5 & Acetate & 16 & Glucose & 27 & Inosine \\
\hline 6 & Glu & 17 & Ser & 28 & NADP $^{+}$ \\
\hline 7 & Glutathione & 18 & Phe & 29 & Pro \\
\hline 8 & Asp & 19 & Tyr & 30 & His \\
\hline 9 & 2 -oxoglutharate & 20 & UDP-Na & 31 & Maltose \\
\hline 10 & Lys & 21 & UDP-diphosphoglucuronate & 32 & GTP \\
\hline 11 & Creatine/phosphocreatine & 22 & NADPH & 33 & malate \\
\hline
\end{tabular}

Table 4. ${ }^{1} \mathrm{HD}$ NMR.

\begin{tabular}{|l|l|l|}
\hline & Increase & Decrease \\
\hline siR neg cont-HIF-1 $\alpha$ & $5,6,26,29,13$ & $23,9,15,17,18,19,28$ \\
\hline siR neg cont-miR-210 & $3,7,11,12,14,18,27$ & $2,5,6,9,13,16,22,24,26$ \\
\hline HIF-1 $\alpha-$ miR-210 & $3,14,15,18$ & $6,9,10,11,13,17,18,19,25,26,27,28,29$ \\
\hline
\end{tabular}

Table 5. Change in total value of metabolites in analysed groups (based on Table 4).
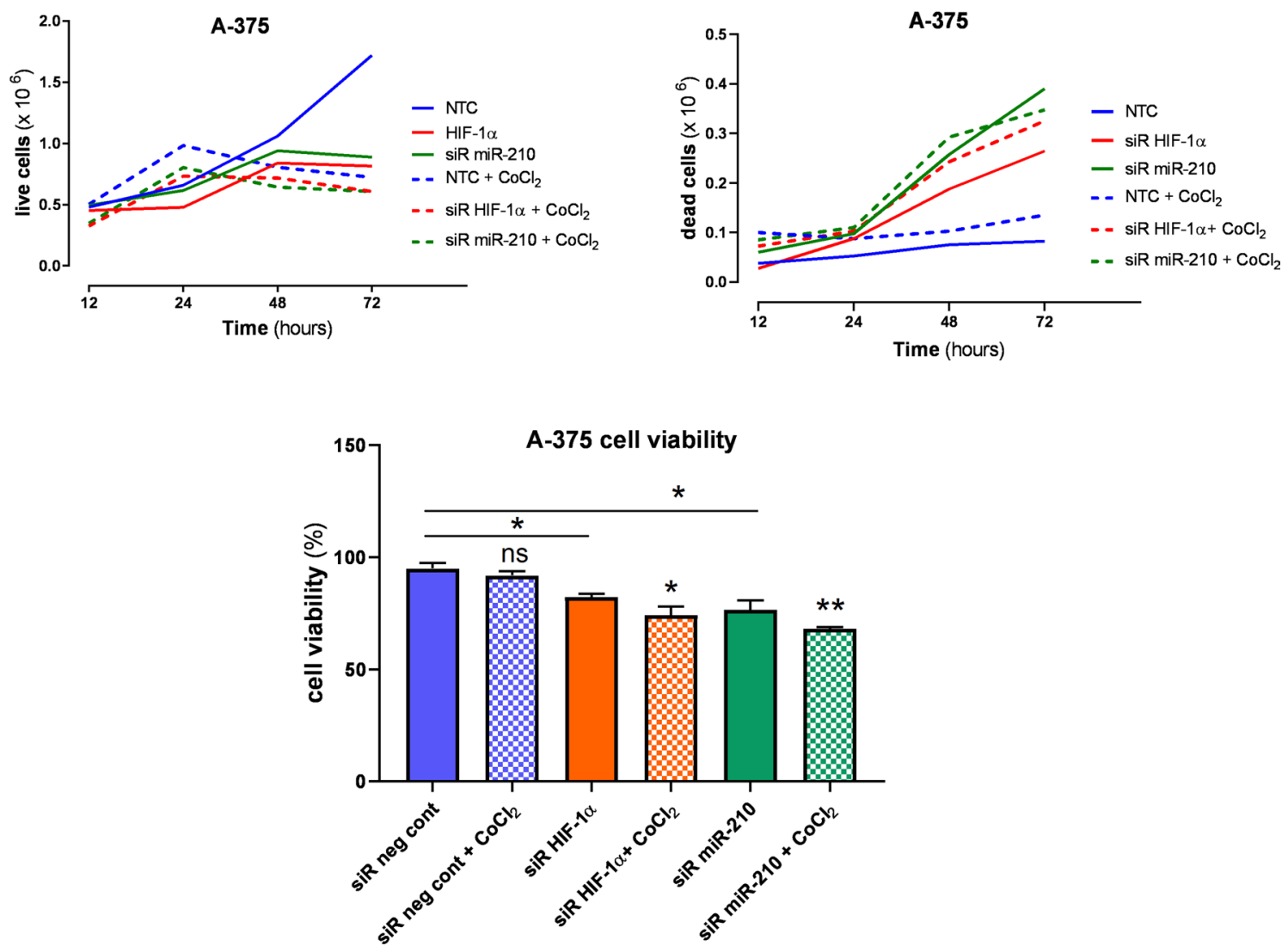

Figure 7. Cell growth line of each analyzed group per live and dead cells (12-72 h); cell viability (48 h). 
regulates PDHA1 expression ${ }^{69}$. As a siRNAs are large, polyaniomic molecules unstable in biological media and are capable of causing unwanted immune response ${ }^{70}$ which can lead to ineffective reduced amount of target protein was used lipoid vector which increased diffusion of target siRNA into a cell because a naked siRNA only partialy passively diffuse through cellular membrane ${ }^{71}$. The low efficiency of siRNA HIF-1 $\alpha$ transfection in melanoma cell line could be because of non-appropriate siRNA concentration, or the serum quality was not sufficient for target siRNA transfection, or the read-out time was not optimal for siRNA HIF-1 $\alpha$ in melanoma cells but it was optimal time window for the rest of experimental condition. As we focused in our study on comparing the effect of gene silencing HIF- $1 \alpha$ and miR-210 on the monitored processes $\left(\mathrm{O}_{2}{ }^{-{ }^{-}}\right.$production, accumulation of $\mathrm{NADH}$ in the cytosol, and the efficiency of mitochondria in ATP production) we think that the less successful gene silencing could have an effect on the preservation of pro-survival effect of the HIF-1a regulatory pathway.

From the general equation of mitochondria ROS generation $\mathrm{NADH}+2 \mathrm{O}_{2} \rightarrow \mathrm{NAD}^{+}+2 \mathrm{O}_{2}^{\cdot-}+\mathrm{H}^{+72}$, an increased concentration of NADH leads to an increased concentration of $\mathrm{O}_{2}{ }^{--}$. Non-physiological overexpression of HIF-1a reduces ROS levels ${ }^{73}$, thereby protecting the cell from oxidative stress-induced apoptosis, thus enhancing tumorigenesis. Some authors claim that the production of $\mathrm{O}_{2}{ }^{-}$could be reduced by suppressing $\mathrm{NADH}$ or by reducing the NADH/NAD ${ }^{+}$ratio $^{74}$. The decrease in the NADH/NAD ${ }^{+}$ratio in the cytosol of cells reflects the change in the energy substrate preference by anaplerotic reactions of citric acid cycle ${ }^{75,76}$. Contrariwise, our experimental measurements show that the reduction of $\mathrm{NADH}$ accumulation, the NADH/NAD ${ }^{+}$ratio, in the cytosol leads to a significantly increased production of $\mathrm{O}_{2}{ }^{--}$in normoxia. Mitochondria which effectively produce ATP have a lower NADH/NAD ${ }^{+}$ratio and their production of ROS depends on local concentration of oxygen, mitochondrial membrane potencial, and the $\mathrm{CoQH}_{2} / \mathrm{CoQ}$ ratio in addition to the NADH/NAD ${ }^{+}$ratio $^{77}$. A relatively low level of the $\mathrm{NADH} / \mathrm{NAD}^{+}$ratio is associated with a low level of the $\mathrm{CoQH} / \mathrm{CoQ}$ ratio and leads to an increase in ROS production through respiratory complex $\mathrm{III}^{78}$. We detected minimal, essentially no change in NADH levels, which again resulted in an increased ROS production in hypoxia, while the increase in the ratio of free $\mathrm{NADH} / \mathrm{NAD}^{+}$in hypoxic conditions reflects the so-called glycolytic metabolism of malignant cells that behave according to Warburg's principles.

All gene manipulations such as gene activation and gene silencing can involve cytotoxicity, but to the best of our knowledge there is no described cytotoxic affect of miR-210 gene silencing. We hypothesize that the observed conditions such as a decrease in the level of the NADH/NAD ${ }^{+}$ratio and an increase in the ROS level are caused by reactivation of the impaired mitochondria metabolism and apoptic processes.

Control cells showed minimal mitochondrial activity in both normoxia and hypoxia ${ }^{79}$, which again corresponds to Warburg's definition ${ }^{80}$. Restriction of the gene activity of hypoxic factors HIF- $1 \alpha$ as well as miR-210 increased mitochondrial viability in both normoxic and hypoxic conditions. We observed a significant increase in ATP-linked respiration, $\mathrm{H}^{+}$-leak, and reverse capacity. Increased OXPHOS mediated by HIFs attenuation leads to increased mitochondrial biogenesis ${ }^{81,82}$. An increase in OXPHOS may also be a manifestation of cell adaptation to the conditions that have arisen, leading to de novo resistance of melanoma cells to inhibitors of the MAPK pathway and subsequently to oxidative stress, so-called combination of inhibition of the MAPK pathway and OXPHOS ${ }^{37}$.

OCR measurements indicate that the significance of silencing of hypoxic factor miR-210 gene products has a similar effect on the activation of respiratory complexes as attenuation of hypoxic factor HIF-1a gene products. The effect of gene silencing is broader in controlling expression of a number of other tumorigenic transcription and growth factors which also belong to miR-210. We also detected a significant increase in basal glycolysis after both the HIF-1 $\alpha$ gene and miR-210 silencing. The proportion of non-glycolytic acidification after silencing of HIF-1a in normo- and hypoxia and miR-210 in normoxia was significant, which may reflect an increased production of acidic metabolites.

Some studies claim that suppressing the expression of hypoxic transcription factors will decrease ROS production ${ }^{19,83,84}$, which we did not observe in our experiments. This atypical trend of increasing ROS activity was shown also by Zhao et al. who reported that inhibitors of HIF-1 inhibit reprogramming of cancer cell from OXPHOS to anaerobic glycolysis, increase intratumoral ROS production, and eventually supress the formation of metastatic tumours ${ }^{85}$. Moreover, the inhibition of miR-210 and its target proteins such as ISCU1/2 also increases ROS production ${ }^{86}$. The downregulation of HIFs and hypoxa-miR can upregulate ROS production by a positive/negative feedback loop ${ }^{87}$. The levels of ROS widely fluctuate during cell life because ROS in cancer cells can increase and decrease based on variations in the expression of SOD in cancer cells ${ }^{88,89}$. This fact can have a large effect on the measured ROS production.

ROS activate various cellular signalling pathways as PI3K/Akt, MAPK, NF- $\kappa \mathrm{B}$, and p53 which play an important role in cell survival and death caused by apoptosis ${ }^{90}$. In addition to the increase in specific gene and protein products, apoptosis can be defined by the presence of characteristic metabolites used to activate apoptotic processes, or the products of an apoptotic process which we uniformly refer to as "find-me" signals ${ }^{91-94}$.

NMR spectra of the metabolites in cells affected by siR HIF- $1 \alpha$ and siR miR-210 show significant changes in the representation of apoptotic signals defined by an increased concentration of amino acids (Ala, Phe, Ser, Glu, etc.) due to the breakdown of cellular organelles, an increase in nucleotides as a manifestation of the breakdown of the cell nucleus, and an increase in carnitine concentration (in some cases it has a protective role against apoptosis/necrosis especially in muscle cells during hard work) which can serve as a stimulant of the apoptotic process in cancer cells, an increase in myo-inositol, UDP-derivates, and alanine ${ }^{95,96}$ compared to siR neg cont cells. Detected increase in mitochondrial activity (using the Seahorse Assay) which led to the accumulation of ROS (analysed by MitoSox) and thus to apoptosis of cells was reflected in an overall decrease in ATP in the cells affected by siRNAs detected by NMR. We also observed an increase in NAD $(\mathrm{P})^{+}$and a decrease in NADH in the NMR spectra of cells affected by gene silencing compared to siR neg cont. This NMR spectral data confirms the measurements obtained with the Peredox m-Cherry Assay, where we similarly observed a decrease in free $\mathrm{NADH}$ and an increase in $\mathrm{NAD}^{+}$. 
In summary, our work shows a direct link between the induction of apoptosis and the elimination of the effect of hypoxic transcription factors in induced pseudohypoxia in MM A375 cells by post-transcriptional repression of the HIF- $1 \alpha$ and miR-210 gene. We observed a significant decrease in the accumulation of free NADH in the cytosol of cells, and an increase in OCR in mitochondrial activity. This phenomenon may be due to the activation of respiratory complexes and thus the use of OXPHOS to generate energy, making more efficient use of cytosolic glycolytic metabolism. ECAR measurements show that glycolysis increased only after HIF-1a attenuation. After inactivation of miR-210, we observed a decrease in glycolytic activity, but an increase in ATP production by the OXPHOS pathway. Activation of respiratory complexes also led to an increase in $\mathrm{O}_{2}{ }^{--}$production and the flushing of "find-me" apoptotic signals. The growth curve data shows that the cells exhibit an increase of apoptotic activity after gene silencing of both HIF- $1 \alpha$ and miR-210. It can be concluded that affected malignant melanoma cells undergo apoptosis or process "death-like" apoptosis by reactivating mitochondrial metabolism.

These findings could be used in the future to develop drugs that target expression of miR-210 (as our data shows a thin connection between miR-210 and HIF-1 $\alpha$ on mitochondria respiratory complexes). The treatment would focus predominantly on those cells that, due to elevated levels of miR-210, detach mitochondrial metabolism from cellular energy production.

\section{Material and methods}

Malignant melanoma cell culture. Amelanotic malignant melanoma cell line A375 (Cell Bank Graz, Medical University of Graz, Austria) was cultured in Dulbecco's Modified Eagle's Medium (DMEM) with $25 \mathrm{mM}$ glucose, $2 \mathrm{mM}$ glutamine, $10 \%$ Fetal Calf Serum (FCS), $100 \mathrm{U} / \mathrm{ml}$ penicillin, $0.1 \mathrm{mg} / \mathrm{ml}$ streptomycin and 1.25 $\mu \mathrm{g} / \mathrm{ml}$ amphotericin in a thermoincubator at $37^{\circ} \mathrm{C}$ and $95 \% \mathrm{O}_{2}, 5 \% \mathrm{CO}_{2}$ atmosphere.

We stimulated the pseudohypoxic environment by adding $100 \mu \mathrm{M} \mathrm{CoCl}_{2} \cdot 6 \mathrm{H}_{2} \mathrm{O}$ to the culture medium for $24 \mathrm{~h}$ after siRNA transfection. Cobalt(II) chloride hexahydrate is a chemical inducer of HIF-1,2,3 ${ }^{95}$ and acts by three different stabilization mechanisms of HIF-1a:

1. $\mathrm{CoCl}_{2}$ stabilizes HIF-1 $\alpha$ through antagonism with $\mathrm{Fe}^{2+}$ which is an essential cofactor along with $\mathrm{O}_{2}$ for $\mathrm{PHD}$ (prolylhydroxylase) which degrades HIF-1a;

2. partial inhibition of PHD and depletion of ascorbate leading to maintenance of HIF-PHD and HIF inhibitory factor (FIH) whereby HIF remains in active form;

3. direct binding of cobalt to HIF-1 $\alpha$, which can protect it from degradation via the VHL-dependent and VHLindependent pathways ${ }^{96}$.

It has also been documented that $\mathrm{CoCl}_{2}$ is involved in the selective activation of HIF-1 $\alpha$ signaling ${ }^{96}$.

Gene silencing and geneticaly encoded biosensores. Gene silencing of HIF-1a and miR-210 was induced overnight $(12 \mathrm{~h}$ ) by adenoviral transfection ( $100 \mathrm{nM}$ of the appropriate siRNA with $2.5 \mu \mathrm{g} / \mathrm{ml}$ TransFast transfection reagent (Promega, Madison, WI, USA)) HIF-1a siRNA in encoded sequence 5'-CCA CCA CUG AUG AAU UAA AUU TT-3 '(Microsynth, Oligo ID \# 2,808,643), and siRNA miR-210 in the coding sequence 5'-UCA GCC GCU GUC ACA CGC ACA GTT-3' (Microsynth, Oligo ID \# 2,808,645), and negative siRNA control (Thermofisher, \# 4,390,843) on A375 malignant melanoma subconfluent cells. The genetically encoded biosensors Peredox-mCherry, and MitoTracker Red CMXRos were transfected with the appropriate plasmid DNA Peredox-mCherry (pcDNA3.1), and MitoTracker Red CMXRos (tetramethylrhodamine methyl ester and 10-N-nonyl acridine orange) into A375 subconfluent cells. Cells which were treated with negative siRNA control ( $\mathrm{siR}$ neg cont) were used as control. The cells were used for analysis after $48 \mathrm{~h}$ of transfection.

mRNA/miRNA isolation and RT-PCR. The peqGOLD total RNA kit (Peqlab; Erlangen, Germany, cat. No.: 12-6834-02) was used to isolate total RNA and miRNA. Isolated nucleic acids were transcribed into cDNA using a cDNA synthesis kit (Applied Biosystems; Foster City, CA) and a thermocycler (Peqlab). RT-PCR amplification was performed using a QuantiFast SYBR Green RT-PCR kit (Qiagen; Hilden, Germany) and LightCycler 480 (Roche Diagnostics; Vienna, Austria). The obtained data were analyzed using REST Software (Qiagen). Relative gene expression was normalized to the housekeeping gene GAPDH, and U6 respectively. The primer sequences are listed in supplementary data (ST 1).

The total number of mRNA molecules varies with cell size, the number of cells, cell metabolic status and cell cycle phase ${ }^{97}$ and thus results in microenvironment higher or lower gene expression, even under gene silencing. The relevancy or effectivity of gene silencing can be „measured” as synergistically up/downregulation of linked genes $^{98,99}$.

Peredox-mCherry T-Sapphire assay. The accumulated NADH/NAD ${ }^{+}$ratio was determined with the genetically encoded Peredox-mCherry T-Sapphire (CFP/YFP) fluorescent biosensor $(1.5 \mu \mathrm{g} / \mathrm{ml}$ plasmid with $2.5 \mu \mathrm{g} / \mathrm{ml}$ TransFast transfection reagent (Promega, Madison, WI, USA)) whose change in fluorescence intensity after NADH molecule binding was detected by Real Time Single Cell Imaging Microscopy LSM Pascal (Zeiss, Germany) with $40 \times-100 \times$ oil immersion objective and optical distance $<1 \mu \mathrm{m}$ with laser excitation of the first wavelength $430 \mathrm{~nm}$ and the second excitation wavelength $570 \mathrm{~nm}$, the excitation time for channel 1 was $200 \mathrm{~ms}$, and for channel 2 was $50 \mathrm{~ms}$. The method is based on a sensitive fluorescent biosensor for changing the NADH/ $\mathrm{NAD}^{+}$ratio combining circulating GFP T-Sapphire with bacterial NADH-binding protein Rex whose fluorescence intensity increases only by reversible binding of NADH to the complex ${ }^{100,101}$. A375 cells were stimulated to produce and consume NADH by adding $500 \mathrm{mM}$ lactate, or $500 \mathrm{mM}$ pyruvate to the extracellular $\mathrm{Na}^{+} / \mathrm{Ca}^{2+}$ 
solution (121.5 mM NaCl, $25 \mathrm{mM} \mathrm{NaHCO}_{3}, 2.5 \mathrm{mM} \mathrm{KCl}, 2 \mathrm{mM} \mathrm{CaCl}_{2}, 1.25 \mathrm{mM} \mathrm{NaH}_{2} \mathrm{PO}_{4}, 1 \mathrm{mM} \mathrm{MgCl}_{2}$ ). We performed measurements in triplicate for each monitored condition.

MitoTracker Red CMXRos assay. MitoTracker Red CMXRos is a passively diffusing permeable probe containing mild thiol-reactive chloromethyl that accumulates in active mitochondria. The determined intensity of red fluorescence produced by $\mathrm{O}_{2}{ }^{--}$by cells incubated with the MitoTracker Red CMXRos biosensor (200 nM MitoTracker Red CMXRos) in the dark for $10 \mathrm{~min}$ before the actual cell measurement. We detected the changes in ROS using confocal spinning disk microscope (Axio Observer.Z1 from Zeiss, Gottingen, Germany) equipped with $100 \times$ objective lens (Plan-Fluor $\times 100 / 1.45$ Oil, Zeiss), a motorized filter wheel (CSUX1FW, Yokogawa Electric Corporation, Tokyo, Japan) on the emission side, AOTF-based laser merge module for laser line 405, 445, 473, 488, 515, and $561 \mathrm{~nm}$ (Visitron Systems), and a Nipkow-based confocal scanning unit (CSUX1, Yokogawa Electric Corporation). Cells A375 with MitoTracker Red CMXRos were alternately excited with $579 \mathrm{~nm}$ laser lines, and emissions were acquired at $599 \mathrm{~nm}$ using a charged CCD camera (Cool SNAP-HQ, Photometrics, Tucson, AZ, USA). Z-stacks of channel in $0.2 \mu \mathrm{m}$ increments were recorded. The VisiView acquisition software (Universal Imaging, Visitron Systems) was used to acquire the imaging data. Modified protocol according to Madreiter-Sokolowski et al. ${ }^{102}$.

Seahorse assay. The mitochondrial activity of A375 cells was detected using the Seahorse Assay. Cells were measured at $100 \%$ confluence in Cell-Tak covered by XF96-96 well polystyrene cell culture microplates (Seahorse Bioscience, Agilent; California, US). We determined the OCR (oxygen consumption rate) and ECAR (extracellular acidification rate) using an XF96 extracellular flow analyzer. The values of OCR and ECAR were measured every $7 \mathrm{~min}$. After $15 \mathrm{~min}$. basal measurements were injected with solutions of $2 \mu \mathrm{M}$ Oligomycin followed by $2.5 \mu \mathrm{M}$ Antimycin. Therefore, we analyzed the OCR data, and the ECAR data was according to the Seahorse XF96 protocol. We performed measurements in triplicate for each monitored condition.

1D ${ }^{1} \mathrm{H}$ NMR. All ${ }^{1} \mathrm{H}^{1} \mathrm{D}$ NMR experiments were performed at $310 \mathrm{~K}$ on a Bruker Avance III $500 \mathrm{MHz}$ spectrophotometer equipped with a TXI probe (Bruker Daltonics, Bremen, Germany). A 1D CPMG pulse sequencer (Carr-Purcell-Meiboom-Gill) with cpmgpr1d parameters, 73,728 points in F1, 12,019.230 Hz spectral width, 2048 pass, with a cyclic delay of 4 secs, was used for the measurement, with water suppression using presaturation. We used the reference chemical database Madison-Qingdao Metabolomics Consortium Database to analyze the obtained metabolites ${ }^{103}$ and all determined metabolites were compared with reference compounds. We acquired, processed, and evaluated the results using Bruker Topspin 3.1, and MestReNova 10.0 software (Mestrelab Research, Santiago de Compostela, Spain). We related the concentration of metabolites to the TSP standard. We performed measurements in triplicate for each monitored condition.

Cell viability. The proliferative capacity and viability of A375 malignant melanoma cells was detected using the Trypan Blue Staining Assay. Cells were seeded at the density of 150,000 per well in a 24-well plate and cultured for $72 \mathrm{~h}$. Cells were transfected with the appropriate siRNA before starting cell proliferation measurements. The percentage of viable cells (at $48 \mathrm{~h}$ ) was calculated according to Sigma-aldrich recommendations ${ }^{104}$.

Statistical analysis. The presented experimental data were evaluated using GraphPad Prism 5.04 and represent the mean values \pm SEM of three independent measurements. Multiple t-test, one-way, and two-way ANOVA was used (Tukey's Multiple Comparison test) for statistical analysis. Statistically significant results were found to have a $P$ value $<0.01$ is statistically significant, a $P$ value $<0.001$ highly significant, a $P$ value $<0.0001$ strongly significant ${ }^{105}$.

Received: 3 September 2020; Accepted: 29 April 2021

Published online: 14 May 2021

\section{References}

1. Yeo, E.-J. Hypoxia and aging. Exp. Mol. Med. 51(6), 1-15. https://doi.org/10.1038/s12276-019-0233-3 (2019).

2. Correia, S. C. et al. Defective HIF signaling pathway and brain response to hypoxia in neurodegenerative diseases: Not an "Iffy" question!. Curr. Pharm. Des. 19(38), 6809-6822. https://doi.org/10.2174/1381612811319380013 (2013).

3. Shimoda, L. A. \& Semenza, G. L. HIF and the lung. Am. J. Respir. Crit. Care Med. 183(2), 152-156. https://doi.org/10.1164/rccm. 201009-1393pp (2011).

4. Urrutia, A. \& Aragonés, J. HIF oxygen sensing pathways in lung biology. Biomedicines 6(2), 68. https://doi.org/10.3390/biome dicines6020068 (2018).

5. Bishop, T. \& Ratcliffe, P. J. HIF hydroxylase pathways in cardiovascular physiology and medicine. Circ. Res. 117(1), 65-79. https:// doi.org/10.1161/circresaha.117.305109 (2015).

6. Simon, M. C., Liu, L., Barnhart, B. C. \& Young, R. M. Hypoxia-induced signaling in the cardiovascular system. Annu. Rev. Physiol. 70(1), 51-71. https://doi.org/10.1146/annurev.physiol.70.113006.100526 (2008).

7. Lee, J. W., Ko, J., Ju, C. \& Eltzschig, H. K. Hypoxia signaling in human diseases and therapeutic targets. Exp. Mol. Med. 51(6), 1-13. https://doi.org/10.1038/s12276-019-0235-1 (2019).

8. Valle-Tenney, R., Rebolledo, D., Acuña, M. J. \& Brandan, E. HIF-hypoxia signaling in skeletal muscle physiology and fibrosis. J. Cell Commun. Signal. 14(2), 147-158. https://doi.org/10.1007/s12079-020-00553-8 (2020).

9. Pisani, D. F. \& Dechesne, C. A. Skeletal muscle HIF-1a expression is dependent on muscle fiber type. J. Gen. Physiol. 126(2), 173-178. https://doi.org/10.1085/jgp.200509265 (2005). 
10. Pucciarelli, D. et al. Hypoxia increases the heterogeneity of melanoma cell populations and affects the response to vemurafenib. Mol. Med. Rep. 13(4), 3281-3288. https://doi.org/10.3892/mmr.2016.4888 (2016).

11. Zbytek, B., Peacock, D. L., Seagroves, T. N. \& Slominski, A. Putative role of HIF transcriptional activity in melanocytes and melanoma biology. Dermato-Endocrinol. 5(2), 239-251. https://doi.org/10.4161/derm.22678 (2013).

12. Rezvani, H. R. et al. HIF-1a in epidermis: Oxygen sensing, cutaneous angiogenesis, cancer, and non-cancer disorders. J. Investig. Dermatol. 131(9), 1793-1805. https://doi.org/10.1038/jid.2011.141 (2011).

13. Pagani, A. et al. Skin rejuvenation through HIF-1a modulation. Plast. Reconstr. Surg. 141(4), 600e-e607. https://doi.org/10.1097/ prs.0000000000004256 (2018)

14. Monteleon, C. L. et al. Lysosomes support the degradation, signaling, and mitochondrial metabolism necessary for human epidermal differentiation. J. Investig. Dermatol. 138(9), 1945-1954. https://doi.org/10.1016/j.jid.2018.02.035 (2018).

15. Ziello, J. E., Jovin, I. S. \& Huang, Y. Hypoxia-Inducible Factor (HIF)-1 regulatory pathway and its potential for therapeutic intervention in malignancy and ischemia. Yale J. Biol. Med. 80(2), 51-60 (2007).

16. Lum, J. J. et al. The transcription factor HIF-1 plays a critical role in the growth factor-dependent regulation of both aerobic and anaerobic glycolysis. Genes Dev. 21(9), 1037-1049. https://doi.org/10.1101/gad.1529107 (2007).

17. Braicu, B. et al. A comprehensive review on MAPK: A promising therapeutic target in cancer. Cancers 11(10), 1618. https://doi. org/10.3390/cancers11101618 (2019).

18. Harvey, A. J. Overview of Cell Signaling Pathways in Cancer. Predictive Biomarkers in Oncology 167-182 (Springer, 2018). https:// doi.org/10.1007/978-3-319-95228-4_12.

19. Kuphal, S., Winklmeier, A., Warnecke, C. \& Bosserhoff, A.-K. Constitutive HIF-1 activity in malignant melanoma. Eur. J. Cancer 46(6), 1159-1169. https://doi.org/10.1016/j.ejca.2010.01.031 (2010).

20. Soni, S. \& Padwad, Y. S. HIF-1 in cancer therapy: Two decade long story of a transcription factor. Acta Oncol. 56(4), 503-515. https://doi.org/10.1080/0284186x.2017.1301680 (2017).

21. Bharath, A. \& Turner, R. Impact of climate change on skin cancer. J. R. Soc. Med. 102(6), 215-218. https://doi.org/10.1258/jrsm. 2009.080261 (2009)

22. Erdei, E. \& Torres, S. M. A new understanding in the epidemiology of melanoma. Expert Rev. Anticancer Ther. 10(11), 1811-1823. https://doi.org/10.1586/era.10.170 (2010).

23. Jensen, E. H., Margolin, K. A., \& Sondak, V. K. Melanoma and Other Skin Cancers. Cancer Network, Home of the Journal Oncology. https://www.cancernetwork.com/view/melanoma-and-other-skin-cancers (2007)

24. Dębniak, T. Familial malignant melanoma-Overview. Hered. Cancer Clin. Pract. 2(3), 123. https://doi.org/10.1186/1897-42872-3-123 (2004).

25. Ford, D. et al. Risk of cutaneous melanoma associated with a family history of the disease. Int. J. Cancer 62(4), 377-381. https:// doi.org/10.1002/ijc.2910620403 (1995).

26. Obrador, E. et al. Oxidative stress and antioxidants in the pathophysiology of malignant melanoma. Biol. Chem. 400(5), 589-612. https://doi.org/10.1515/hsz-2018-0327 (2019).

27. Yuan, T.-A. et al. Race-, age-, and anatomic site-specific gender differences in cutaneous melanoma suggest differential mechanisms of early- and late-onset melanoma. Int. J. Environ. Res. Public Health 16(6), 908. https://doi.org/10.3390/ijerph16060908 (2019).

28. Stanienda-Sokol, K. et al. Primary locations of malignant melanoma lesions depending on patients' gender and age. Asian Pac. J. Cancer Prev. https://doi.org/10.22034/APJCP.2017.18.11.3081 (2017).

29. Joosse, A. et al. Gender differences in melanoma survival: Female patients have a decreased risk of metastasis. J. Investig. Dermatol. 131(3), 719-726. https://doi.org/10.1038/jid.2010.354 (2011).

30. Matthews, N. H. et al. Epidemiology of Melanoma. Cutaneous Melanoma: Etiology and Therapy 3-22 (Codon Publications, 2017). https://doi.org/10.15586/codon.cutaneousmelanoma.2017.ch1.

31. Melanoma - The Facts [Internet]. Melanoma Patient Network Europe; c2019 [updated 2019; cited 2020 May 8]. Available from: http://www.melanomapatientnetworkeu.org/melanoma.html

32. Sandru, A., Vinea, S., Panaitescu, E. \& Blidaru, A. Survival rates of patients with metastatic malignant melanoma. J. Med. Life 7(4), 572-576 (2014).

33. Burrows, N., Babur, M., Resch, J., Williams, K. J. \& Brabant, G. Hypoxia-inducible factor in thyroid carcinoma. J. Thyroid Res. 2011, 1-17. https://doi.org/10.4061/2011/762905 (2011).

34. Cantwell-Dorris, E. R., O'Leary, J. J. \& Sheils, O. M. BRAFV600E: Implications for carcinogenesis and molecular therapy. Mol. Cancer Ther. 10(3), 385-394. https://doi.org/10.1158/1535-7163.mct-10-0799 (2011).

35. Ascierto, P. A. et al. The role of BRAF V600 mutation in melanoma. J. Transl. Med. 10, 85. https://doi.org/10.1186/1479-587610-85 (2012).

36. Möller, K. et al. MITF has a central role in regulating starvation-induced autophagy in melanoma. Sci. Rep. https://doi.org/10. 1038/s41598-018-37522-6 (2019).

37. McQuade, J. L. \& Vashisht Gopal, Y. Counteracting oxidative phosphorylation-mediated resistance of melanomas to MAPK pathway inhibition. Mol. Cell. Oncol. 2(3), e991610. https://doi.org/10.4161/23723556.2014.991610 (2015).

38. Liu, L., Fu, M., Pei, S., Zhou, L. \& Shang, J. R-Fluoxetine increases melanin synthesis through a 5-HT1A/2A receptor and p38 MAPK signaling pathways. Int. J. Mol. Sci. 20(1), 80. https://doi.org/10.3390/ijms20010080 (2018)

39. De Vita, V.T., Hellman, S., Rosenberger, S.A. eds. Cancer: Principles and Practise of Oncology. 8th ed. Lipincot Williams and Wilkins, a Wolter Kluwer nosiness (2008).

40. Sini, M. C. et al. Genetic alterations in main candidate genes during melanoma progression. Oncotarget 9(9), 8531-8541. https:// doi.org/10.18632/oncotarget.23989 (2018).

41. Zhang, J. et al. ROS and ROS-mediated cellular signaling. Oxid. Med. Cell. Longev. 2016, 1-18. https://doi.org/10.1155/2016/ 4350965 (2016).

42. Sharma, L., Lu, J. \& Bai, Y. Mitochondrial respiratory complex I: Structure, function and implication in human diseases. Curr. Med. Chem. 16(10), 1266-1277. https://doi.org/10.2174/092986709787846578 (2009).

43. Urbańska, K. \& Orzechowski, A. Unappreciated role of LDHA and LDHB to control apoptosis and autophagy in tumor cells. Int. J. Mol. Sci. 20(9), 2085. https://doi.org/10.3390/ijms20092085 (2019).

44. Cannino, G., Ciscato, F., Masgras, I., Sánchez-Martín, C. \& Rasola, A. Metabolic plasticity of tumor cell mitochondria. Front. Oncol. https://doi.org/10.3389/fonc.2018.00333 (2018).

45. Grivennikova, V. G. \& Vinogradov, A. D. Partitioning of superoxide and hydrogen peroxide production by mitochondrial respiratory complex I. Biochim. Biophys. Acta (BBA) Bioenerg. 1827(3), 446-54. https://doi.org/10.1016/j.bbabio.2013.01.002 (2013).

46. Korge, P., Calmettes, G., John, S. A. \& Weiss, J. N. Reactive oxygen species production induced by pore opening in cardiac mitochondria: The role of complex III. J. Biol. Chem. 292(24), 9882-9895. https://doi.org/10.1074/jbc.m116.768317 (2017).

47. Korge, P., Calmettes, G. \& Weiss, J. N. Reactive oxygen species production in cardiac mitochondria after complex I inhibition: Modulation by substrate-dependent regulation of the NADH/NAD+ ratio. Free Radic. Biol. Med. 96, 22-33. https://doi.org/10. 1016/j.freeradbiomed.2016.04.002 (2016). 
48. Sharkia, I. et al. Pyruvate dehydrogenase has a major role in mast cell function, and its activity is regulated by mitochondrial microphthalmia transcription factor. J. Allergy Clin. Immunol. 140(1), 204-214.e8. https://doi.org/10.1016/j.jaci.2016.09.047 (2017).

49. Ratnikov, B. I., Scott, D. A., Osterman, A. L., Smith, J. W. \& Ronai, Z. A. Metabolic rewiring in melanoma. Oncogene 36(2), 147-157. https://doi.org/10.1038/onc.2016.198 (2016).

50. Fischer, G. M. et al. Metabolic strategies of melanoma cells: Mechanisms, interactions with the tumor microenvironment, and therapeutic implications. Pigment Cell Melanoma Res. 31(1), 11-30. https://doi.org/10.1111/pcmr.12661 (2017).

51. Iommarini, L., Porcelli, A. M., Gasparre, G. \& Kurelac, I. Non-canonical mechanisms regulating hypoxia-inducible factor 1 alpha in cancer. Front. Oncol. https://doi.org/10.3389/fonc.2017.00286 (2017).

52. Ježek, J., Cooper, K. \& Strich, R. Reactive oxygen species and mitochondrial dynamics: The Yin and Yang of mitochondrial dysfunction and cancer progression. Antioxidants 7(1), 13. https://doi.org/10.3390/antiox7010013 (2018).

53. Gatterer, H. et al. Exercise performance, muscle oxygen extraction and blood cell mitochondrial respiration after repeated-sprint and sprint interval training in hypoxia: A pilot study. J. Sports Sci. Med. 17(3), 339-347 (2018)

54. Iommarini, L. et al. Different mtDNA mutations modify tumor progression in dependence of the degree of respiratory complex I impairment. Hum. Mol. Genet. 23(6), 1453-1466. https://doi.org/10.1093/hmg/ddt533 (2013).

55. Kelly, T. J., Souza, A. L., Clish, C. B. \& Puigserver, P. A hypoxia-induced positive feedback loop promotes hypoxia-inducible factor 1 stability through miR-210 suppression of glycerol-3-phosphate dehydrogenase 1-like. Mol. Cell. Biol. 31(13), $2696-2706$. https://doi.org/10.1128/mcb.01242-10 (2011).

56. Choudhry, H. \& Harris, A. L. Advances in hypoxia-inducible factor biology. Cell Metab. 27(2), 281-298. https://doi.org/10. 1016/j.cmet.2017.10.005 (2018).

57. Li, P., Jiao, J., Gao, G. \& Prabhakar, B. S. Control of mitochondrial activity by miRNAs. J. Cell. Biochem. 113(4), 1104-1110. https://doi.org/10.1002/jcb.24004 (2012).

58. Babu, K. R. \& Tay, Y. The Yin-Yang regulation of reactive oxygen species and microRNAs in cancer. Int. J. Mol. Sci. 20(21), 5335. https://doi.org/10.3390/ijms20215335 (2019).

59. O'Hagan, K. A. et al. PGC-1 is coupled to HIF-1 -dependent gene expression by increasing mitochondrial oxygen consumption in skeletal muscle cells. Proc. Natl. Acad. Sci. 106(7), 2188-2193. https://doi.org/10.1073/pnas.0808801106 (2009).

60. Cai, F.-F. et al. Prognostic value of plasma levels of HIF-1a and PGC-1a in breast cancer. Oncotarget 7(47), 77793-77806. https:// doi.org/10.18632/oncotarget.12796 (2016).

61. Zhang, T. et al. Mitf is a master regulator of the v-ATPase, forming a control module for cellular homeostasis with v-ATPase and TORC1. J. Cell Sci. 128(15), 2938-2950. https://doi.org/10.1242/jcs.173807 (2015).

62. Checinska, A. \& Soengas, M. S. The gluttonous side of malignant melanoma: basic and clinical implications of macroautophagy. Pigment Cell Melanoma Res. 24(6), 1116-1132. https://doi.org/10.1111/j.1755-148x.2011.00927.x (2011).

63. Slominski, R. M., Zmijewski, M. A. \& Slominski, A. T. The role of melanin pigment in melanoma. Exp. Dermatol. 24(4), 258-259. https://doi.org/10.1111/exd.12618 (2015).

64. Veliká, B., Birková, A., Hubková, B., Valko-Rokytovská, M. \& Mareková, M. Mitochondrial diseases connected with electron transport system deficiencies and its application in diagnostic process. Egészségtudományi Közlemények J. Health Sci. 8(1), 51-57 (2018).

65. Sun, J. et al. Overexpression of pyruvate dehydrogenase E1 $\alpha$ subunit inhibits warburg effect and induces cell apoptosis through mitochondria-mediated pathway in hepatocellular carcinoma. Oncol. Res. Featuring Preclin. Clin. Cancer Ther. 27(4), 407-414. https://doi.org/10.3727/096504018x15180451872087 (2019).

66. Špaková, I. et al. Hypoxia factors suppression effect on the energy metabolism of a malignant melanoma cell SK-MEL-30. Eur. Rev. Med. Pharmacol. Sci. 24(9), 4909-4920. https://doi.org/10.26355/eurrev_202005_21180(2020).

67. Hartman, M. L. \& Czyz, M. MITF in melanoma: Mechanisms behind its expression and activity. Cell. Mol. Life Sci. 72(7), 1249-1260. https://doi.org/10.1007/s00018-014-1791-0 (2014).

68. Louphrasitthiphol, P. et al. MITF controls the TCA cycle to modulate the melanoma hypoxia response. Pigment Cell Melanoma Res. 32(6), 792-808. https://doi.org/10.1111/pcmr.12802 (2019).

69. Manoj, K. M. Debunking chemiosmosis and proposing murburn concept as the operative principle for cellular respiration. Biomed. Rev. 28, 31. https://doi.org/10.14748/bmr.v28.4450 (2018).

70. Chernikov, I. V., Vlassov, V. V. \& Chernolovskaya, E. L. Current development of siRNA bioconjugates: From research to the clinic. Front. Pharmalocol. https://doi.org/10.3389/fphar.2019.00444 (2019).

71. Reischl, D. \& Yimmer, A. Drug delivery of siRNA therapeutics: Potentials and limits of nanosystems. Nanomed. Nanotechnol. Biol. Med. 5(1), 8-20. https://doi.org/10.1016/j.nano.2008.06.001 (2009).

72. Li, H.-S. et al. HIF-1 $\alpha$ protects against oxidative stress by directly targeting mitochondria. Redox Biol. 25, 101109. https://doi. org/10.1016/j.redox.2019.101109 (2019).

73. Onukwufor, J. O., Berry, B. J. \& Wojtovich, A. P. Physiologic implications of reactive oxygen species production by mitochondrial complex I reverse electron transport. Antioxidants 8(8), 285. https://doi.org/10.3390/antiox8080285 (2019).

74. Vander Heiden, M. G. \& DeBerardinis, R. J. Understanding the intersections between metabolism and cancer biology. Cell 168(4), 657-669. https://doi.org/10.1016/j.cell.2016.12.039 (2017).

75. Rabinovich, S. et al. The mitochondrial carrier Citrin plays a role in regulating cellular energy during carcinogenesis. Oncogene 39(1), 164-175. https://doi.org/10.1038/s41388-019-0976-2 (2019).

76. Murphy, M. P. How mitochondria produce reactive oxygen species. Biochem. J. 417(1), 1-13. https://doi.org/10.1042/bj20081386 (2008).

77. Korge, P., Calmettes, G., John, S. A. \& Weiss, J. N. Reactive oxygen species in cardiac mitochondria: the role of complex III. J Biol Chem. 292(24), 9896-9905 (2017).

78. Porporato, P. E., Filigheddu, N., Pedro, J.M.B.-S., Kroemer, G. \& Galluzzi, L. Mitochondrial metabolism and cancer. Cell Res. 28(3), 265-280. https://doi.org/10.1038/cr.2017.155 (2017).

79. Senyilmaz, D. \& Teleman, A. A. Chicken or the egg: Warburg effect and mitochondrial dysfunction. F1000Prime Rep. 7, 1. https:// doi.org/10.12703/p7-41 (2015).

80. Thomas, L. W. \& Ashcroft, M. Exploring the molecular interface between hypoxia-inducible factor signalling and mitochondria. Cell. Mol. Life Sci. 76(9), 1759-1777. https://doi.org/10.1007/s00018-019-03039-y (2019).

81. Karshovska, E. et al. HIF-1a (Hypoxia-Inducible Factor-1a) promotes macrophage necroptosis by regulating miR-210 and miR-383. Arterioscler. Thromb. Vasc. Biol. 40(3), 583-596. https://doi.org/10.1161/atvbaha.119.313290 (2020).

82. Du, Y. et al. Curcumin inhibits cancer-associated fibroblast-driven prostate cancer invasion through MAOA/mTOR/HIF-1 $\alpha$ signaling. Int. J. Oncol. 47(6), 2064-2072. https://doi.org/10.3892/ijo.2015.3202 (2015).

83. Irwin, D. C. et al. A potential role for reactive oxygen species and the HIF-1a-VEGF pathway in hypoxia-induced pulmonary vascular leak. Free Radic. Biol. Med. 47(1), 55-61. https://doi.org/10.1016/j.freeradbiomed.2009.03.027 (2009).

84. Zhao, T. et al. HIF-1-mediated metabolic reprogramming reduces ROS levels and facilitates the metastatic colonization of cancers in lungs. Sci. Rep. https://doi.org/10.1038/srep03793 (2014).

85. Kim, J. H., Park, S. G., Song, S.-Y., Kim, J. K. \& Sung, J.-H. Reactive oxygen species-responsive miR-210 regulates proliferation and migration of adipose-derived stem cells via PTPN2. Cell Death Dis. 4(4), e588-e588. https://doi.org/10.1038/cddis.2013. 117 (2013). 
86. Kwee, J. K. A paradoxical chemoresistance and tumor suppressive role of antioxidant in solid cancer cells: A strange case of Dr. Jekyll and Mr. Hyde. BioMed Res. Int. 2014, 1-9. https://doi.org/10.1155/2014/209845 (2014).

87. Kim, E.-K. et al. Redox-mediated mechanism of chemoresistance in cancer cells. Antioxidants 8(10), 471. https://doi.org/10. 3390/antiox8100471 (2019).

88. Zhou, D., Shao, L., \& Spitz, D. R. Reactive oxygen species in normal and tumor stem cells. in Advances in Cancer Research 1-67 (Elsevier, 2014). https://doi.org/10.1016/B978-0-12-420117-0.00001-3.

89. Redza-Dutordoir, M. \& Averill-Bates, D. A. Activation of apoptosis signalling pathways by reactive oxygen species. Biochim. Biophys. Acta (BBA) Mol. Cell Res. 1863(12), 2977-92. https://doi.org/10.1016/j.bbamcr.2016.09.012 (2016).

90. Ravichandran, K. S. Find-me and eat-me signals in apoptotic cell clearance: progress and conundrums. J. Exp. Med. 207(9), 1807-1817. https://doi.org/10.1084/jem.20101157 (2010).

91. Halama, A., Riesen, N., Möller, G., Hrabě de Angelis, M. \& Adamski, J. Identification of biomarkers for apoptosis in cancer cell lines using metabolomics: tools for individualized medicine. J. Intern. Med. 274(5), 425-439. https://doi.org/10.1111/joim.12117 (2013).

92. Mason, E. F. \& Rathmell, J. C. Cell metabolism: An essential link between cell growth and apoptosis. Biochim. Biophys. Acta (BBA) Mol. Cell Res. 1813(4), 645-54. https://doi.org/10.1016/j.bbamcr.2010.08.011 (2011).

93. Matsuura, K., Canfield, K., Feng, W., \& Kurokawa, M.. Metabolic regulation of apoptosis in cancer. in International Review of Cell and Molecular Biology 43-87 (Elsevier, 2016). https://doi.org/10.1016/bs.ircmb.2016.06.006.

94. Flusberg, D. A. \& Sorger, P. K. Surviving apoptosis: Life-death signaling in single cells. Trends Cell Biol. 25(8), 446-458. https:// doi.org/10.1016/j.tcb.2015.03.003 (2015).

95. Wenzel, U., Nickel, A. \& Daniel, H. Increased carnitine-dependent fatty acid uptake into mitochondria of human colon cancer cells induces apoptosis. J. Nutr. 135(6), 1510-1514. https://doi.org/10.1093/jn/135.6.1510 (2005).

96. Wu, D. \& Yotnda, P. Induction and testing of hypoxia in cell culture. J. Vis. Exp. https://doi.org/10.3791/2899 (2011).

97. Zhang, Y.-B. et al. The effects of $\mathrm{CoCl} 2$ on HIF-1 $\alpha$ protein under experimental conditions of autoprogressive hypoxia using mouse models. Int. J. Mol. Sci. 15(6), 10999-11012. https://doi.org/10.3390/ijms150610999 (2014).

98. Marinov, G. K. et al. From single-cell to cell-pool transcriptomes: Stochasticity in gene expression and RNA splicing. Genome Res. 24(3), 496-510. https://doi.org/10.1101/gr.161034.113 (2013).

99. Leung, R. K. M. \& Whittaker, P. A. RNA interference: From gene silencing to gene-specific therapeutics. Pharmacol. Ther. 107(2), 222-239. https://doi.org/10.1016/j.pharmthera.2005.03.004 (2005).

100. Rajeevkumar, S., Anunanthini, P. \& Sathishkumar, R. Epigenetic silencing in transgenic plants. Front. Plant Sci. https://doi.org/ 10.3389/fpls.2015.00693 (2015).

101. Depaoli, M. R. et al. Live cell imaging of signaling and metabolic activities. Pharmacol. Ther. 202, 98-119. https://doi.org/10. 1016/j.pharmthera.2019.06.003 (2019).

102. Zhao, Y. \& Yang, Y. Profiling metabolic states with genetically encoded fluorescent biosensors for NADH. Curr. Opin. Biotechnol. 31, 86-92. https://doi.org/10.1016/j.copbio.2014.08.007 (2015).

103. Madreiter-Sokolowski, C. T. et al. Enhanced inter-compartmental Ca2+flux modulates mitochondrial metabolism and apoptotic threshold during aging. Redox Biol. 20, 458-466. https://doi.org/10.1016/j.redox.2018.11.003 (2019).

104. Cui, Q. et al. Metabolite identification via the Madison Metabolomics Consortium Database. Nat. Biotechnol. 26(2), 162-164. https://doi.org/10.1038/nbt0208-162 (2008).

105. Van den Bossche, J., Baardman, J. \& de Winther, M. P. J. Metabolic characterization of polarized M1 and M2 bone marrowderived macrophages using real-time extracellular flux analysis. J. Vis. Exp. 10, 5. https://doi.org/10.3791/53424 (2015).

\section{Acknowledgements}

We would like to give special thanks to František Badovský who contributed the graphical version of picture no. 1.

\section{Author contributions}

S.I. conceived the study with major imput from G.W. and M.M.; S.I. performed most of the experiments; R.M. further edited upon input from all co-authors; M.H. funded the article.

\section{Funding}

The data presented was generated in one PhD thesis. The work was supported by the dsv Open Med.

\section{Competing interests}

The authors declare no competing interests.

\section{Additional information}

Supplementary Information The online version contains supplementary material available at https://doi.org/ 10.1038/s41598-021-89792-2.

Correspondence and requests for materials should be addressed to M.R.

Reprints and permissions information is available at www.nature.com/reprints.

Publisher's note Springer Nature remains neutral with regard to jurisdictional claims in published maps and institutional affiliations.

Open Access This article is licensed under a Creative Commons Attribution 4.0 International

License, which permits use, sharing, adaptation, distribution and reproduction in any medium or format, as long as you give appropriate credit to the original author(s) and the source, provide a link to the Creative Commons licence, and indicate if changes were made. The images or other third party material in this article are included in the article's Creative Commons licence, unless indicated otherwise in a credit line to the material. If material is not included in the article's Creative Commons licence and your intended use is not permitted by statutory regulation or exceeds the permitted use, you will need to obtain permission directly from the copyright holder. To view a copy of this licence, visit http://creativecommons.org/licenses/by/4.0/.

(c) The Author(s) 2021 